\title{
China in rätoromanischen Zeitungen, Zeitschriften und literarischen Texten
}

\section{China in Romansh Newspapers, Magazines and Literature}

Political events from China were discussed astonishingly often in Romansh newspapers from 1840 to 1950. Unlike the Catholic newspapers, the liberal press often endorsed a pro-Chinese position, since they were defending an anti-imperialist, anti-missionary attitude. Impressive reports were written in the 1930s by A. Volkart-Christoffel for the newspaper La Casa Pater$n a$, conveying real scenes from China to the public, such as the bombing of Shanghai or the Nanjing Massacre of 1937. From the 1950s onwards, political news from China gradually disappeared from the newspapers - except regarding the occupation of Tibet, which caused a negative response to Chinese politics. From the 1980s onwards, such news reports were increasingly replaced by stories from Romansh speakers who travelled to China or lived there. Unlike political events, Chinese culture was rarely discussed. Nevertheless, Chinese elements can be found in the literary work of over twenty Romansh authors, and parallels can be recognised in this context between Romansh newspapers and literature. The Boxer War of 19001901, for example, which was particularly well reported on in the newspapers, was the topic of poems written in 1901 by Giovannes Mathis, Chasper Po and Alfons Tuor. Just as travel reports from China gained importance in newspapers from the 1980s onwards, so too did they assume importance in literature. Chinese poems themselves were also presented in Romansh by Gian Fadri Caderas as early as 1887.

Der vorliegende Text entstand auf Grundlage von ungefähr 2000 Dokumenten zum allgemeinen Thema »China in rätoromanischen Zeitungen, Zeitschriften und literarischen Texten « - gefunden in der Bibliothek der Chesa Planta in Samedan - und alle Behauptungen wurden, so weit möglich, induktiv aus dem gesammelten Material abgeleitet. Einige Dokumente mögen übersehen worden sein, da von den rätoromanischen Periodika nur drei Zeitungen digitalisiert vorlagen, der Rest aber durchzublättern war. Der Text hat eine chronologische Struktur, wobei in der ersten Hälfte vor allem Zeitungen und Zeitschriften, in der zweiten dann literarische Texte behandelt werden. 


\section{Tschin wird fromm ${ }^{1}$}

Ob Rätoroman*innen im 19. Jahrhundert und früher nach China auswanderten, ist zurzeit noch unbekannt. ${ }^{2}$ Ab den 1980er Jahren, in der Ära des Deng Xiaoping 鄧小平 (1904-1997), vor allem aber in den letzten fünfzehn Jahren, wohnten und wirkten hingegen einige Rätoroman*innen in China, darunter Diplomat*innen, Köchinnen, Künstler*innen, Sportler*innen, Handwerkerinnen oder Forscher ${ }^{\star}$ innen und Student*innen. ${ }^{3}$ Anton Velleman, der ab 1918 an der Universität Genf Rätoromanisch unterrichtete, ${ }^{4}$ hatte China als Reisender in den 1920er Jahren besucht ${ }^{5}$ und A. Volkart-Christoffel, Korrespondent für die Casa Paterna, lebte zwischen 1934 und 1939 in Shanghai, 1908 aber in Harbin in der Mandschurei. ${ }^{6}$ Ebenfalls länger verweilten in China Missionar*innen. Der bekannteste rätoromanische Missionar mag Üjop Freinadametz (1852-1908) gewesen sein, unter chinesischen Christ*innen Sheng Fu Ruose 聖福若瑟 genannt, aber da er aus den ladinischen Dolomiten stammt, spielt er für unseren Text, der China in der bünderromanischen Kultur behandelt, keine Rolle. ${ }^{7}$

Viele christliche Missionar*innen im China des 19. bis Mitte des 20. Jahrhunderts fühlten sich gegenüber den Chinesinnen kulturell und religiös überlegen.

1 Für Kritik, für Hinweise sowie einen Austausch über chinesische und rätoromanische Themen bedanke ich mich herzlich bei Dumenic Andry, Renzo Caduff, Silvana Derungs, Rico Valär und Marc Winter.

2 Hinweise zu Rätoroman*innen, die in asiatische Länder auswanderten, allerdings nicht nach China, gibt es bei Ernst Lechner: Die periodische Auswanderung der Engadiner und anderer Bündner, Samaden: Engadin Press Co., 1912, S. 77-81; Dolf Kaiser: Cumpatriots in terras estras. Prouva d'üna documentaziun davart l'emigraziun grischuna, considerand in speciel l'Engiadina e contuorns, Samedan: Stamparia engiadinaisa, 1968, S. 15f., 69, 134, 139-141; Peter Michael-Caflisch: Hier hört man keine Glocken. Geschichte der Schamser Auswanderung nach Amerika und Australien, Baden: hier + jetzt, 2008, S. 174-178. Ebenfalls keine Erwähnung zu China bei Reto Caratsch: Grischuns a l'ester. Glorias e misiergias da trais seculs d'emigraziun, in: ders.: Ouvras, Zernez: Ediziun dal Chardun, 1983, S. 183-217 oder Rahel Seraina Schreich: Süllas passidas da l'emigraziun jaura dal 18avel tschientiner fin a la prüma guerra mundiala, Sta. Maria: R. S. Schreich, 2004-2005.

3 Vgl. z. B. Casa Paterna, 1989, Nr. 25; Fögl Ladin, 1. März 1988, 15. und 26. März 1991; Calender Romontsch, 1989, S. 158, 1992, S. 266-281; La Quotidiana, 6. November 1999, 16. Juni 2004, 8. Juli 2006, 8. November 2007, 30. Mai 2008, 15. Januar 2010, 28. August 2011,6. und 15. Juni, 3., 6., 12., 17. und 24. Juli, 30. Oktober, 26. November 2012, 4. September 2014, 17. März, 28. April, 30. Juli, 3. September 2015, 19. Januar, 22. Dezember 2016; Calender Per mintga gi, 2014, S. 117-122.

Ab 1932 war Anton Velleman Professor für Rätoromanisch an der Universität Genf, unterrichtete dort Rätoromanisch aber bereits 1918. Für den Hinweis herzlichen Dank an Renzo Caduff.

5 Vgl. Fögl d'Engiadina, 28. November 1930, 30. August 1932.

6 Vgl. Casa Paterna, 1935, Nr. 21 und siehe S. 94-97 in diesem Beitrag.

7 Für den Hinweis auf Üjop Freinadametz bedanke ich mich herzlich bei Rut Bernardi. 
Die jesuitische Methode der Akkomodation ${ }^{8}$ gehörte der Vergangenheit an. "Es geht uns nur um das eine «, meinte der Berner Pfarrer Ernst Buss, der 1884 zu den Gründern der Ostasien-Mission gehörte, »dass Jesus Herr und Helfer der ganzen Menschheit werde «, ${ }^{9}$ und der Missionar Ludivic Maria Paly (Clau Mudest Paly) aus Cumpadials hoffte noch 1932, eingeschlossen zwischen den Kriegen der Guomindang, Kommunist ${ }^{\star}$ innen und Japaner ${ }^{\star}$ innen, so naiv das klingen mag, »da cristianisar l'entira massa chinesa cura che l'ura destinada dalla Providientscha ei arrivada " (»die gesamte chinesische Masse zu christianisieren, wenn die Stunde der göttlichen Vorsehung gekommen is $«$ ). ${ }^{10}$ Zur Ausbildung der Missionar*innen bei der Basler Mission gehörte keine Auseinandersetzung mit der chinesischen Kultur, gerne aber wurde die Überlegenheit des Christentums gelehrt. ${ }^{11}$ Um die Ideologie der Mission zu verstehen, genügt wohl die Lektüre eines Kinderbuches, nämlich Albert Ostertags Tschin, der arme Chinesenknabe. Dieses Buch erschien auch auf Rätoromanisch: 1855 in Basel unter dem Titel Tschin, il pover giuven chines, als Kuriosum im Format von ungefähr $10 \times 7 \mathrm{~cm}$ und einem Umfang von 31 Seiten. Übersetzer war Anton Mohr, der hie und da in Tschlin im Unterengadin Predigten hielt ${ }^{12}$ (Abbildung 1).

Tschin beginnt mit einer Beschreibung von Shanghai:

N’ella China s'rechatta üna granda et vasta citat con nom Schanghai, situada zuond strusch al mar, chi contegnia in sai blers millis habitants. Zuond granda ais in quaista la miseria, la povertad et l'empietad. Lasupra non pudain nus ins smüravglar, perche Schanghai ais üna citat pajana, n’ella quala ch’ün non cognoscha noss benedi Salvader. ${ }^{13}$

8 Vgl. Weijian Liu: Kulturelle Exklusion und Identitätsentgrenzung. Zur Darstellung Chinas in der deutschen Literatur 1870-1930, Bern: Peter Lang, 2007 (Deutsch-Ostasiatische Studien zur interkulturellen Literaturwissenschaft, Bd. 7), S. 101; Thoralf Klein: Aktion und Reaktion? Mission und chinesische Gesellschaft, in: Kolonialkrieg in China. Die Niederschlagung der Boxerbewegung 1900-1901, hg. von Mechthild Leutner und Klaus Mühlhahn, Berlin: Christoph Links, 2007, S. 32-42, hier S. 33; Adrian Hsia: China-Bilder in der europäischen Literatur, Würzburg: Königshausen \& Neumann, 2010 (Saarbrücker Beiträge zur vergleichenden Literatur- und Kulturwissenschaft, Bd. 49), S. 14-26; Daniela Li: China als Muse. Produktive Rezeption chinesischer Literatur und Kultur in der deutschen Literatur des 20. und 21. Jahrhunderts, Berlin: Christian A. Bachmann, 2015 (Studia Comparatistica, Bd. 5), S. 137-149.

9 Vgl. Otto Marbach: 50 Jahre Ostasienmission. Ihr Werden und Wachsen, Berlin/St. Gallen: Ostasienmission, 1934, S. 9.

10 Vgl. Gasetta Romontscha, 1. Dezember 1932. Übersetzungen von MG, wo nicht anders angegeben.

11 Vgl. Thoralf Klein: Die Basler Mission in Guangdong (Südchina) 1859-1931. Akkulturationsprozesse und kulturelle Grenzziehung zwischen Missionaren, chinesischen Christen und lokaler Gesellschaft, München: Iudicium, 2002, S. 107, 122, 129-131.

12 Vgl. Anton Mohr: Predgias evangelicas salvadas a Celin, Samaden: Stamparia Tanner, 1897.

13 Albert Ostertag: Tschin, il pover giuven chines, übers. von Anton Mohr, Basel: J.J. Mast, 1855, S. 1; die folgenden Zitate im Text in dieser Reihenfolge auf S. 4, 8, 13, 15, 20, $27,22$. 


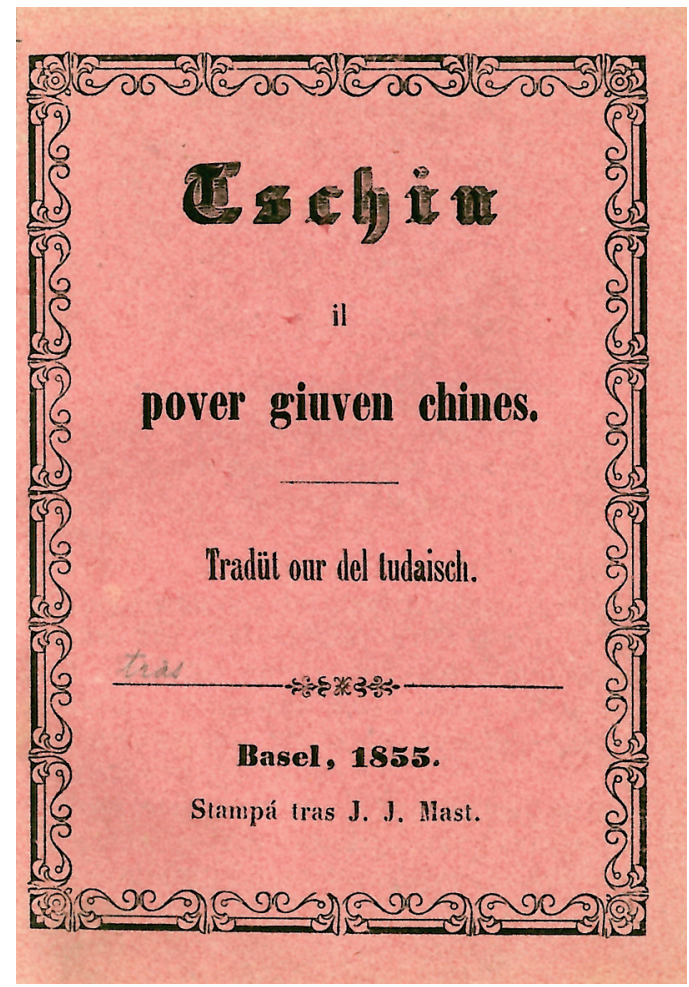

Abb. 1: Titelblatt der rätoromanischen Version von Tschin

In China gibt es eine große, gewaltige Stadt, die heißt Schanghai. Es liegt hart am Meere und wimmelt von vielen tausend Menschen, die darin wohnen. Es ist aber auch unbeschreiblich viel Elend, Armut und Gottlosigkeit in dieser Stadt; und das ist nicht zu verwundern, denn es ist eine Heidenstadt, wo man den seligmachenden Namen Jesu nicht kennt. ${ }^{14}$

In dieser dreckigen Stadt wächst Tschin auf, und da seine Eltern und Verwandten gottlos und verschlagen sind, wird auch sein Herz, wie sollte es anders sein, »corruot dal tössi del puchiá et della malizia« (»von dem Gift der Sünde und der Bosheit durchdrungen«). 1840 erobern Engländer, »wohlmeinende Fremde«, die Stadt, denn »ils Chines als fettan bler dal mal« ([sie hätten] »allerlei Gewalt und Schaden von den Chinesen erlitten«). Nachdem Tschin die Engländer vor einer vorsätzlichen Vergiftung rettet, kann er mit ihnen nach England fahren. Auf dem Schiff lernt er, sich "à disciplina, ad uorden et ad obedienza" ("an Zucht, Ordnung und Gehorsam«) zu gewöhnen. In England dann geschieht eine seltsame Wandlung. Aus dem 
frechen Tschin wird, nachdem er vom »unic vair Dieu et da seis filg Jesu Christo" (»vom wahrhaftigen Gott und seinem Sohn Jesus, dem Heiland der Sünder«) hört, erst recht aber, als er "missionar Smith, preschantamaing ovaisch da Hongkong" (»Bischoff Smith von Hongkong, der damals noch Missionar [...] war «) trifft, ein frommer Knabe, der ständig betet und, während die anderen Kinder Dummheiten anstellen, in einer Ecke die Bibel liest. Er wünscht sich eine Taufe, ändert seinen Namen auf John Dennis und möchte Missionar werden, "perche eug non poss supportar l'impissamaint, cha meis compatriots s'rechiatan n'ell ignoranzia, n'el puchià et n'ella miseria " (»denn ich kann den Gedanken nicht ertragen, dass meine Landsleute in Unwissenheit, Sünde und Elend liegen «). Daraus wird aber nichts. John alias Tschin erkrankt schwer und bekommt »chiafuolas plajas, chi bütteivan à saimper oura blera materia« (»tiefe Wunden, die immer viel Eiter entleerten«). Die Schmerzen sowie durch begangene Sünden verursachte psychische Qualen erträgt er, indem er Psalmen liest; ohnehin seien seine Schmerzen »inguotta in comparatium con que cha Jesus ha soffert per mai« (»nichts gegen das, was Jesus für mich gelitten«). Kurze Zeit später stirbt er, ist aber gerettet.

Tschins Erzählung fasst ein paar Annahmen der Missionsdoktrin zusammen: Die Europäer*innen sind wohlwollend und haben die chinesischen Städte zu Recht besetzt. Die Chines*innen mögen gehorchen, die Missionar*innen als Heilsbringer sehen, beten und an christliche Dogmen glauben, vor allem sich selber als Sünder ${ }^{*}$ innen begreifen, sich taufen lassen, den Namen ändern und vergangene Lebensweisen aufgeben, selber missionieren und Landsleute zum Christentum überreden, Leiden, Schmerzen und den Tod akzeptieren. Es ist nicht überraschend, dass diese nicht gerade fröhlichen Ideen bei vielen Chines ${ }^{\star}$ innen wenig Begeisterung auslösten, vielleicht auch vor dem Hintergrund einer komplexen Logik in der buddhistischen und daoistischen Philosophie sowie den Erinnerungen an Hong Xiuquan 洪秀全 (1814-1864), der sich als jüngerer Bruder von Jesus verstand und dessen Taiping-Lehre 1851-1864 zu einem Bürgerkrieg mit 20 bis 30 Millionen Toten führte. ${ }^{15}$ Die Missionar*innen besaßen zudem Sonderrechte, konnten etwa Boden ohne Absprache mit den Behörden erwerben, genossen Exterritorialität und standen außerhalb des chinesischen Gesetzes. Sie spalteten durch Geld und Infrastruktur - dadurch auch für die chinesischen Eliten eine Konkurrenz - Dörfer und Familien in christliche und nichtchristliche Einheiten und konnten jederzeit mit militärischen Interventionen der Schutzmächte drohen. ${ }^{16}$ Deshalb kam es hie und

16 Zu diesen Punkten vgl. z. B. Klaus Mühlhahn: China und der westliche Imperialismus, in: Kolonialkrieg in China. Die Niederschlagung der Boxerbewegung 1900-1901, hg. von Mechthild Leutner und Klaus Mühlhahn, Berlin: Christoph Links, 2007, S. 15-26, hier S. 20 f.; Klein: Aktion und Reaktion?, S. 33; Sabine Dabringhaus: Die Boxer. Motivation, Unterstützung und Mobilisierung, in: Kolonialkrieg in China. Die Niederschlagung der Boxerbewegung 1900-1901, hg. von Mechthild Leutner und Klaus Mühlhahn, Berlin: Christoph Links, 2007, S. 60-68, hier S. 61; Klein: Die Basler Mission in Guangdong, S. 244-248. 
da zu Angriffen gegen sie, aber noch mehr gegen chinesische Christ ${ }^{\star}$ innen, vor allem während des Boxeraufstands 1900 und des Bürgerkriegs der 1920er und 1930er Jahre.

\section{Unangenehmes Leben in China}

Die Sursilvanerinnen Thomasa Monn und Carmelina Paly aus Cumpadials reisten 1920, begleitet von fünf weiteren Nonnen, vom Dominikanerinnen-Kloster in Glion (Ilanz) nach Shanghang in Fujian, wo sie eine Schule für Mädchen gründeten. Innerhalb von wenigen Wochen hätte Thomasa »disciplinau la giuventetgna chinesa (»die chinesische Jugend diszipliniert «). ${ }^{17}$ Bereits zwei Jahre später starb sie, bei einer Hitze von $35{ }^{\circ} \mathrm{C}$ an Pocken oder einer Hirnhautentzündung, eine »biala, sontga mort en tutta dolur ed encarschadetgna (»einen schönen, heiligen Tod in all seinem Schmerz und seiner Wehmut $«),{ }^{18}$ meinte der Autor Carli Fry, der in der Gasetta Romontscha auch für den Faschismus und Antisemitismus warb. ${ }^{19}$ Die Zeitschrift Il Pelegrin von 1922 enthält eine schöne Todesanzeige mit chinesischen Schriftzeichen, die in rätoromanischen Periodika nur selten zu finden sind. Um die Todesanzeige sind - als wären sie an Holzplatten aufgehängt - drei Spruchbänder mit weiteren Zeichen zu sehen; umrahmt wird das Ganze von einem Trauerflor aus Bambusstücken (Abbildung 2).

Die drei Zeichen im oberen Spruchband, tong gong dan 通功單, bedeuten in etwa »Bekanntmachungszettel von Verdiensten « und werden insbesondere bei katholischen Todesanzeigen verwendet. ${ }^{20}$ Der Spruch auf dem rechten Band könnte in etwa lauten: »Wer geboren wird und Kinder aufnimmt und unterrichtet, überwindet damit die Welt des Alltäglichen «, jener auf dem linken: »Wer spricht entsprechend der Tugend des Herrn, kehrt [Zeichen unklar] in sein ursprüngliches Heimatland zurück«. Einem Nachruf dann entspricht der eigentliche Text, der schildert, wie die Verstorbene in der Schweiz geboren wurde, Kinder unterrichtete und am 26. Juli mit 47 Jahren starb.

1924, zwei Jahre nach Thomasa Monn, starb im Alter von 32 Jahre auch Carmelina Paly, nach "gronds quitaus, grevas lavurs, il sgarscheivel clima, la trita vivonda» ("großen Sorgen, schweren Arbeiten, dem schrecklichen Klima, der

18 Vgl. ebd., S. 171.

19 Vgl. Adolf Collenberg: Der Atem des Faschismus im Spiegel der romanischen Presse 19221937, in: Bündner Monatsblatt. Zeitschrift für bündnerische Geschichte und Landeskunde, Chur: Desertina, 1988, Nr. 6, S. 347-363, hier S. 348. Für den Hinweis, dass es sich beim Autor»---y« um Carli Fry (1897-1956) handelt, bedanke ich mich herzlich bei Silvana Derungs. Zu Fry siehe auch http://e-lir.ch/index.php?id=963\&lemma=fry\&chavazzin=\&lang=r (Zugriff 04.09.2020).

20 Für die Analyse und Übersetzung der chinesischen Todesanzeige bedanke ich mich herzlich bei Marc Winter. 


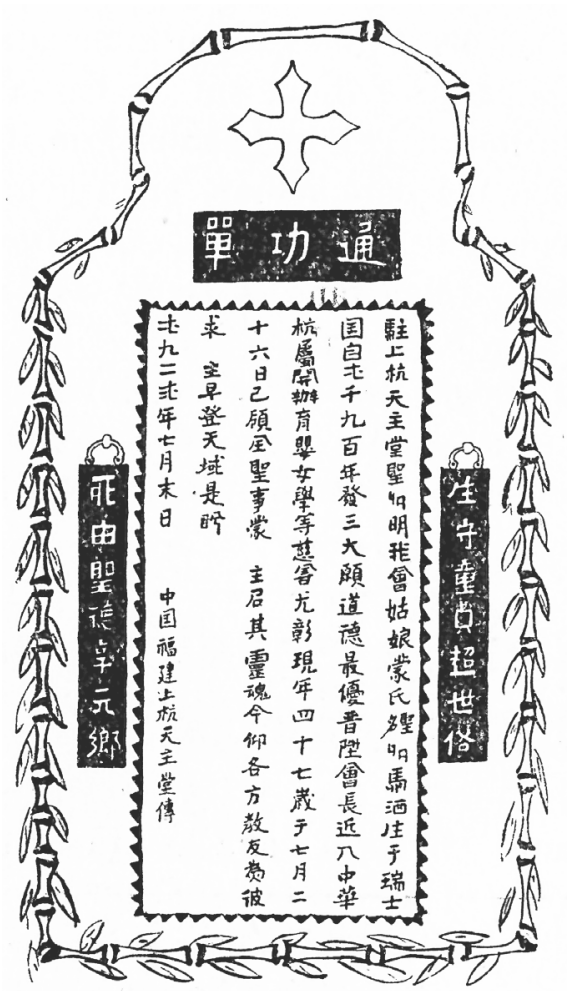

Abb. 2: Todesanzeige für Thomasa Monn, in: Il Pelegrin, 1922, S. 171

grässlichen Nahrung «) ${ }^{21}$ Ihr Bruder Ludivic Maria, der - wie oben geschildert auf eine Christianisierung der gesamten chinesischen Bevölkerung hoffte, ${ }^{22}$ erreichte China im Winter 1923 und wirkte 1927, in Zeiten des Bürgerkriegs, in Wuping in der Provinz Fujian. ${ }^{23}$ Statt wie andere Missionar*innen zu fliehen, ${ }^{24}$ blieb er in China und verschwand 1933. Er sei zwischen Unterdrückerinnen, Rebellinnen und Kommunist ${ }^{\star}$ innen geraten, in ein Gefängnis geworfen, gefoltert und umgebracht worden, heißt es in einer Quelle, ${ }^{25}$ von Bandit ${ }^{\star}$ innen ermordet und, um Spuren zu verwischen, in einen Fluss geworfen, in einer anderen. ${ }^{26}$ Kaum war der Zweite Weltkrieg beendet, reisten weitere Missionar*innen aus der Surselva nach China. Sie alle

21 Gasetta Romontscha, 30. Oktober 1924, vgl. La Quotidiana, 16. März 2012, 10. Oktober 2017.

22 Vgl. Gasetta Romontscha, 1. Dezember 1932.

23 Vgl. Gasetta Romontscha, 13. November 1924, 25. Mai, 2. und 7. Juni 1927, 1. Dezember 1932.

24 Vgl. Gasetta Romontscha, 17. März 1927.

25 Vgl. La Quotidiana, 10. Oktober 2017.

26 Vgl. La Quotidiana, 22. Dezember 2015; zum Leben eines weiteren Missionars, Oskar Maria Jäger aus Sur, Surses vgl. Gasetta Romontscha, 3. August 1950. 
verließen das Land spätestens im Jahr 1954, als die Volksrepublik die Missionen schloss, und flohen nach Taiwan oder Japan. ${ }^{27}$ Obschon die Bestrebungen der sursilvanischen Missionar*innen in China insgesamt ein Misserfolg waren - $2015 \mathrm{kehr}$ ten auch noch die letzten Nonnen aus Taiwan zurück ${ }^{28}$-, werden sie von der katholischen Presse regelmäßig präsentiert. Noch im 21. Jahrhundert werden ehemalige Missionar*innen als Märtyrer ${ }^{*}$ innen bezeichnet ${ }^{29}$ und kommen Predigten zur Veröffentlichung, die so klingen, als hätte sie Tschin im 19. Jahrhundert diktiert. ${ }^{30}$

\section{Lieber Chinapartys als Missionierung}

In anderen rätoromanischen Gegenden, stellvertretend sei das Engadin genannt, war der Missionsgedanke nicht besonders beliebt, ja wurde er zum Teil offen verspottet. Nach Meinung des Chinesen Kgau, so wird im Chalender grischun von 1858 erzählt, hatte Jesus zwei Gesellschaften: »La prüma societad havet el pro sia naschíta, qua eiran bocs et asens e la segonda societad eira pro sia fin, qua eiran morders e laders« (»Die erste Gesellschaft hatte er bei seiner Geburt, dort waren Böcke und Esel, und die zweite bei seinem Ende, dort waren Mörder und Diebe«). ${ }^{31}$ Wie erfolglos im Engadin die Werbung der Missionare war, lässt sich ferner anhand der Rezensionen ihrer zahlreichen Vorträge - sie fanden zwischen 1902 und 1939 statt - in der Engadiner Zeitung Fögl d'Engiadina nachverfolgen. ${ }^{32}$ Zwei Beispiele seien genannt. Nur wenige Knochen hätten den Missionsvortrag Ende April 1922 besucht, aber hätte es irgendein »climbim« gehabt, wäre der Andrang sicher größer gewesen. ${ }^{33}$ Dr. Witte aus Berlin sprach im September 1923 in Zernez, begleitet wurde er von seinem Assistenten Dr. Hemmi, der mit einem Apparat Bilder projizierte. Es gab zwei Vorträge, einen am Nachmittag für die Kinder, die allerdings das Deutsche kaum verstanden, und einen für Erwachsene am Abend. Der Abendvortrag sei gut besucht gewesen, aber nur vom »sesso feminin e da divers giuvnets (»weiblichen Geschlecht und einigen Jugendlichen«): »ils baps chattan plü attracziun pro oters locals, inua cha trumpf e stöck giovan la rolla prinzipala « (»die Väter finden mehr Vergnügen in anderen Lokalen, wo Trumpf und Stöck die Hauptrolle spielen «). ${ }^{34}$

Vgl. Calender Romontsch, 1989, S. 147-173; Casa Paterna, 1987, Nr. 5; La Quotidiana, 6. November 2001, 17. März 2002, 9. Oktober 2008, 16. März 2012.

28 Vgl. La Quotidiana, 19. November 2015.

29 Vgl. z. B. La Quotidiana, 7. November 2000.

30 Vgl. La Quotidiana, 15. Februar 2002, vgl. auch ebd., 4. Februar 2000.

31 Chalender grischun, 1858, S. [24f.].

32 Für die folgenden Ausführungen vgl. Fögl d'Engiadina, 21. Juni 1902, 29. Juni 1912, 7. Dezember 1920, 28. April, 6. Oktober 1922, 21. und 25. September 1923, 25. September, 2. Oktober, 20. November 1925, 14., 17. und 21. Juni 1927, 14. Januar, 11. März 1930, 22. Januar 1932, 24. und 31. August 1934, 1. Februar, 28. März 1938, 7. Juli 1939.

33 Vgl. Fögl d'Engiadina, 28. April 1922.

34 Fögl d'Engiadina, 25. September 1923. 
Zwischen dem 17. und 20. Juni 1927 war eine Wanderausstellung der Ostasienmission im Schulhaus von Samedan zu Gast. ${ }^{35}$ Sie enthielt auch chinesische Kunstwerke aus dem Altertum und sei, meinte Otto Marbach, wie nichts anderes geeignet »den Missionsgedanken zu vertiefen, Missionsinteressen zu fördern und Missionsliebe zu beleben $«{ }^{36}$ In jedes Haus kam eine Broschüre, Plakate wurden überall ausgehängt, und als besondere Propaganda startete von Samedan aus eine Automobiltour »a Schlarigna e Puntraschigna, l'automobil chargio da spüras mattas e mattetas >chinaisas e giapanaisas « ${ }^{37}$ (»nach Celerina und Pontresina, das Automobil gefüllt mit lauter >chinesischen und japanischen` Mädchen«). Die als Chinesinnen und Japanerinnen verkleideten Engadinerinnen, die vermutlich ständig lachten, passten gut zur Chinoiserie der 1920er Jahre. Vielleicht sangen sie auch noch »-tsching, -tschang, -tschung, -ding, -dong ${ }^{38}{ }^{38}$ denn solche Abfolgen von Nonsense-Wörtern, ähnlich wie einige Bünder ${ }^{\star}$ innen von »tschuntsch da tschantsch « und dergleichen sprechen, um das Rätoromanische zu infantilisieren, wurden in der Rätoromanischen Chrestomathie als >chinesische Kinderverse bezeichnet. ${ }^{39}$ Turandot, princessa da China gehörte 1925 und 1931 zu den eingeübten Stücken der Societed dramatica da Samedan, ${ }^{40}$ zudem fanden abends in den Sälen der Engadiner Grand Hotels, etwa im Suvretta House in St. Moritz (Abbildung 3), ${ }^{41}$,Chinabälle oder >Chinesische Nächte`statt. Die Besucher*innen kamen als Chines*innen verkleidet, und die Salonorchester spielten, unterstützt von Ganztonleitern, pentatonischen Tonfolgen und erweitertem Instrumentarium, >exotische`Musik.

Trotz großer Werbung der Ostasienmission war die Ausstellung 1927 in Samedan samt dazugehörigem Vortrag von »frequentaziun discreta« (»diskreter Frequentierung «). ${ }^{42}$ Es lohne sich zwar, die Ausstellung anzuschauen, denn China und Japan »dvaintan viepü naziuns chi giovan lur rolla nell'istoria mondiela« (»entwickeln sich mehr und mehr zu Nationen, die ihre Rolle in der Weltgeschichte spielen«), aber der Grund der Ausstellung, nämlich vom Publikum - auch durch Verkauf von Sachen - »qualche modest obolo« (»einen bescheidenen Obolus«) für die Mission zu bekommen, ${ }^{43}$ schreckte wohl etliche ab. Der Verkauf von Tee und Ta-

Vgl. dazu Fögl d'Engiadina, 14., 17. und 21. Juni 1927.

Vgl. Marbach: 50 Jahre Ostasienmission, S. $92 \mathrm{f}$.

Fögl d'Engiadina 21. Juni 1927.

Vgl. La Quotidiana, 23. Juni 2020; vgl. auch Alfons Tuor: Il Doctor per forza (Le médecin malgré lui). Ina cumedia en 3 acts da Molière, translatada libramein en romonsch, in: Annalas da la Societad Retorumantscha 9 (1894), S. 49-92, hier S. 77; Alfons Tuor: Il Gierau de Schlans. Cumedia originala ord l'ujara franzosa en 1 act, Cuera: Stamparia de Jos. Casanova, 1897, S. 9. Für die Hinweise zu Alfons Tuor herzlichen Dank an Renzo Caduff.

9 Vgl. Caspar Decurtins (Hg.): Rätoromanische Chrestomathie, Bd. 15 (Register), bearbeitet von Peter Egloff und Jon Mathieu, Chur: Octopus Verlag, 1986, S. 123 sowie ebd., Bd. 2, S. 213.

Vgl. Fögl d'Engiadina, 13. Februar 1925, 6. März 1931.

Für den Hinweis herzlichen Dank an Dora Filli und Laura Rezzoli.

Vgl. Fögl d'Engiadina, 21. Juni 1927.

Fögl d'Engiadina, 17. Juni 1927. 


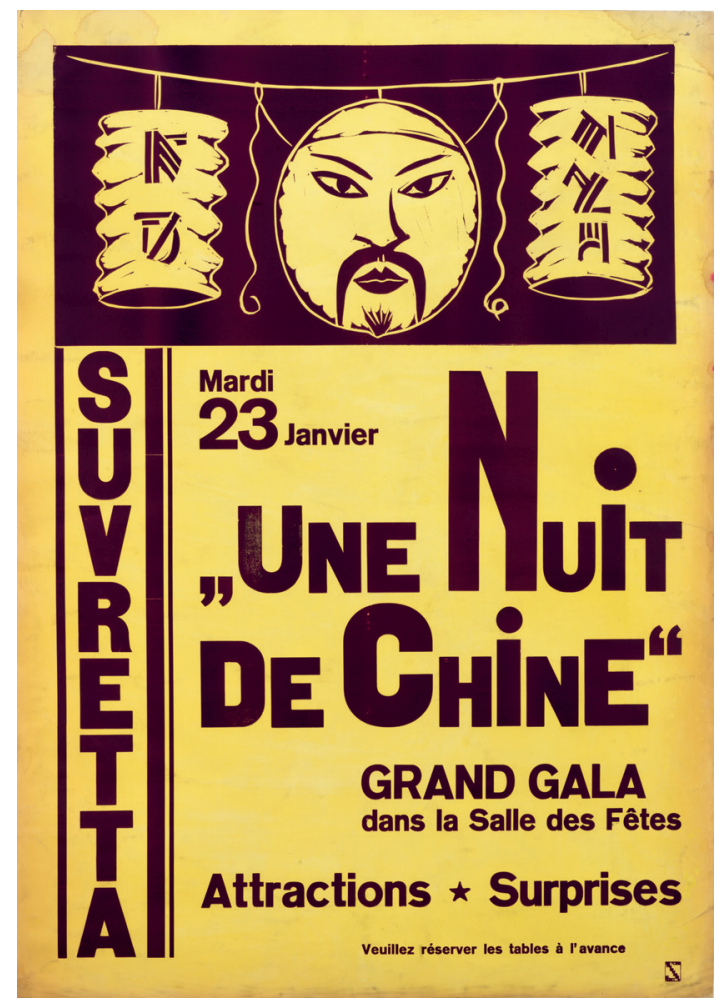

Abb. 3: Chinaparty im Suvretta House St. Moritz - mit pseudochinesischen Zeichen auf den Lampions, 1930er Jahre, Dokumentationsbibliothek St. Moritz,

Nachlass Hugo Wetzel, $99 \times 70 \mathrm{~cm}$

peten während der Ausstellung wurde als eine Konkurrenz für die einheimischen Geschäfte kritisiert. ${ }^{44}$ Und statt Vorträge über die Mission zu hören, würden viele eher den Besuch des Kinos bevorzugen. ${ }^{45}$ Schließlich zeigte sich zeitgleich zur Ausstellung in Samedan eine ornithologische Besonderheit, nämlich eine weiße Amsel, welche die Leute eher ins Freie lockte. ${ }^{46}$

\section{Für oder gegen den Imperialismus}

Da nun Mission und Politik im China des 19. und frühen 20. Jahrhunderts untrennbar miteinander verstrickt waren, die Staaten den Missionar*innen durch militärische Ge-

45 Als Alternativprogramm zu China vgl. auch Fögl d'Engiadina, 13. November 1923, 28. November 1930. 
walt sich in China auszubreiten halfen und letztere wiederum weitere militärische Schläge legitimierten, ${ }^{47}$ wäre es naheliegend, dass die katholischen Periodika in der Surselva eine Position für den europäischen Imperialismus in China einnahmen, die des Engadins aber eine dagegen. Dies zeichnet sich in den Quellen genauso ab, wenn wir uns ein paar politische Berichte insbesondere der beiden größten rätoromanischen Zeitungen des 19. Jahrhunderts anschauen, der Gasetta Romontscha (1857-1996; im Folgenden GR) aus der Surselva und des Fögl d'Engiadina (1857-1940; im Folgenden FE) aus dem Engadin.

Als 1839 der Erste Opiumkrieg ausbrach, gab es im Engadin - die um 1700 gegründete erste Zeitung Graubündens, die Gazetta ordinaria da Scuol stellte ihr Erscheinen bereits um 1730 ein $^{48}$ - weder das FE noch eine andere Zeitung. Von 1843 bis 1844 erschien L'Aurora d'Engiadina ${ }^{49}$ Sie veröffentlichte am 6. Juni 1843 einen Teil der Rede eines gewissen Elepeo, comissari del imperadur, general della Garnison da Canton \&c«. Der chinesische Herrscher hätte die Engländer mit einer »beneficenza« (»Wohltätigkeit») behandelt, wie sie nur vom Himmel verwendet werde, "cun buntà ed amiaivlezza» (»mit Güte und Freundlichkeit»)..$^{50} \mathrm{Um}$ dem Leiden, dem sein Volk ausgesetzt gewesen wäre, jedoch ein Ende zu setzen, hätte er Erneuerungen der Handelsbeziehungen gegenüber den Engländern zugestanden (»concess üna renovatiun dellas relatiuns mercantilas «), das heißt dem ungleichen Vertrag von Nanjing im Herbst 1842 zugestimmt. Diese Passage aus der Aurora d'Engiadina ist insofern merkwürdig, weil sie aufzeigt, wie die Engadiner Zeitungen bereits beim Ersten Opiumkrieg eine pro-chinesische oder aber eine anti-imperialistische Position einnahmen. Letztere zeigte sich dann besonders bei den Kommentaren des FE zum Französisch-Chinesischen Krieg 1884/85.

Am 6. September 1884 wird die französische »opressiun inguriusa, [...] quaist nouv e sfrunto abüs della forza (»erniedrigende Unterdrückung, [...] dieser neue und unverschämte Missbrauch der Macht«) angeklagt, ebenso die Lügen und Vorwände zur Rechtfertigung. "La Frauntscha continua a der lezchas da civilisaziun alla China in bombardand citeds« (»Frankreich setzt für China seine Lektionen zur

47 "Also endlich haben uns die Chinesen den schon von Marschall, ihrem Vorgänger, so lang ersehnten Grund und ¿Zwischenfall k geboten. Ich beschloss, sofort zuzugreifen «, schrieb Kaiser Wilhelm II. an Staatssekretär Bernhard von Bülow, nachdem 1897 zwei Missionare in Shandong ermordet worden waren. Vgl. Herward Sieberg: China im Zeitalter des Imperialismus, in: Der Boxerkrieg in China. Tagebuchaufzeichnungen des späteren Hildesheimer Polizeioffiziers Gustav Paul, hg. von Hubert Mainzer und Herward Sieberg, Hildesheim: Gebrüder Gerstenberg, 2001 (Quellen und Dokumentationen zur Stadtgeschichte Hildesheims, Bd. 11), S. 13-54, hier S. 35 .

48 Vgl. Anna Maria Cantieni: Geschichte der rätoromanischen Presse in Graubünden, Vaz: A. M. Cantieni, 1984, S. 10-12; Jakob Candreia: Die romanische und italienische Journalistik, Bern: Jent \& Co., 1896, S. 3 f.

49 Für einen Überblick zu den rätoromanischen Zeitungen vgl. Cantieni: Geschichte der rätoromanischen Presse in Graubünden, S. $56 \mathrm{f}$.

50 L'Aurora d'Engiadina, 6. Juni 1843. 
Erlernung der Zivilisation fort und bombardiert Städte«) heißt es später, ${ }^{51}$ und kritisiert werden nicht allein die gegenüber China ausgeführten Gewalttaten, sondern auch jene gegenüber französischen Müttern und ihren Söhnen, die sich nicht etwa für die Verteidigung ihres Landes opfern würden, »mo per motivs bger main plausibels" (»aber für viel weniger nachvollziehbare Gründe«). ${ }^{52}$ Der entrüstende Ton in der Anklage, vielleicht auch die Empathie für die Mütter ${ }^{53}$ der Soldaten, könnte auf die Urheberschaft von Gian Fadri Caderas (1830-1891) hinweisen, der zwischen 1880 und 1891 Hauptredaktor des FE war. Er hat als Erster chinesische Lyrik ins Rätoromanische übertragen (siehe Ziffer 11) und war vielleicht dazu Autor einer Anklage gegen die Versklavung chinesischer Arbeiter, die im FE am 16. März 1872 erschien..$^{54}$

Il commerci cun sclevs nairs traunter l'Africa e l'America nun exista pü; ma invece dals nairs africauns haun uossa ils povers abitants della China da giover üna rolla simila. Quaists sclevs moderns as clamman Coolies. Daspö l'ann 1847 sun stos tramiss be a Cuba (America spagnöla) na main da $109^{\prime} 000$ da quaists Coolies a circa 350 dollars per testa. Tenor contract avessan els be da servir durante ün tschert numer d'anns. Ma quasi üngüns vezzan darcho lur patria. La granda maggiorited dad els serva inavaunt vitadurante. Telas chosas arrivan auncha nel famus secul del progress. ${ }^{55}$

Der Handel mit schwarzen Sklaven zwischen Afrika und Amerika existiert nicht mehr; statt den schwarzen Afrikanern haben jetzt die armen Bewohner von China eine ähnliche Rolle zu spielen. Diese modernen Sklaven nennen sich Coolies. Seit dem Jahr 1847 sind alleine nach Kuba (Lateinamerika) nicht weniger als $109^{\prime} 000$ dieser Coolies, für ungefähr 350 Dollar pro Kopf, geschickt worden. Gemäß Vertrag hätten sie nur eine bestimmte Anzahl von Jahren zu dienen. Aber so gut wie keiner sieht seine Heimat wieder. Die große Mehrheit von ihnen dient lebenslang. Solche Sachen geschehen noch im famosen Jahrhundert des Fortschritts.

52 Fögl d'Engiadina, 21. März 1885, vgl. auch ebd., 4. April 1885.

53 Vgl. Mildred Elizabeth Maxfield: Studies in Modern Romansh Poetry in the Engadine, with Special Consideration of Zaccaria Pallioppi (1820-1873), Gian Fadri Caderas (1830-1891) and Peider Lansel (1863-), Cambridge, MA: M. E. Maxfield, 1938, S. 70. Vgl. auch Andrea Vital: Gian Fadri Caderas, in: Annalas da la Societad Retorumantscha 13 (1899), S. 1-36, hier S. 27.

54 Zur Situation der Chinesen als Zwangsarbeiter*innen vgl. auch Jonathan D. Spence: Chinas Weg in die Moderne, übers. von Gerda Kurz und Siglinde Summerer, Bonn: Bundeszentrale für politische Bildung, 2008, S. 262.

Fögl d'Engiadina, 16. März 1872. 
Der französische Angriff auf Tonkin erhielt in der GR eine andere Rezeption. Nicht die Angriffe der Europäer auf China wurden kritisiert, hingegen fast durchwegs jene der Chines ${ }^{\star}$ innen auf Missionar*innen und Christ*innen. Am 21. Februar 1884 erfahren wir zum Beispiel von der Ermordung eines Geistlichen, 22 Katecheten und 215 Gläubigen. Zudem seien 108 ihrer Häuser abgebrannt worden. Im August 1884 wird die Zerstörung der chinesischen Flotte bei Fuzhou vorgestellt, die Franzosen »hagien dau nagin pardun« (»hätten kein Pardon gekannt «) ${ }^{56}$ und gleich alles bombardiert.

Als die Deutschen Ende 1897 die Bucht bei Jiaozhou besetzten und infolgedessen ihre Macht in Shandong ausbauten, entwickelte sich nach und nach der Boxeraufstand, wofür es vielfache Gründe gab. Der Hass gegen die Missionar*innen als Repräsentant*innen der Fremdherrschaft und christlichen Ideologie, gerade in jener Gegend, aus welcher Konfuzius stammte, ${ }^{57}$ war sicher ein Grund - aber auch selbstverschuldete Naturkatastrophen wie Überflutungen, die Wanderungen, Hungersnöte und Armut auslösten, ohne dass die ausgebeutete Regierung finanzielle Mittel für Hilfsaktionen gehabt hätte. Ferner zählen eine Art von Han-Nationalismus, der auch gegen die regierende Mandschu-Dynastie gerichtet gewesen sein mag, das Verlieren traditioneller Arbeit durch Industrie sowie neugebaute Eisenbahnlinien, dadurch auch eine Ablehnung der Modernisierung und dergleichen Gründe mehr dazu. ${ }^{58}$ Die Boxer*innen, infolge ihrer Ausbreitung zuerst von der Qing-Regierung unterstützt, ${ }^{59}$ begannen gegen alles Ausländische zu kämpfen und ermordeten viele christliche Chines ${ }^{\star}$ innen, hie und da auch europäische Missionar^innen.

\section{Unterschiedliche Ansichten des Boxerkriegs}

Die geradezu konträre Haltung zwischen der GR und dem FE hinsichtlich China und der Missionsbewegung zeigt sich am besten in ihren Berichten zum Boxeraufstand und späteren Boxerkrieg. Beginnen wir mit den Berichten aus dem Sommer 1900, als nach der Ermordung des Diplomaten Clemens von Ketteler ${ }^{60}$ auch die Falschmeldung der Ermordung aller Gesandt*innen durch die Boxer*innen in Beijing - zur Legitimation des alliierten Rachefeldzugs - verbreitet wurde. ${ }^{61}$ Die GR ersann am 19. Juli 1900 in einem Artikel namens "La massacra de tuts ambassadurs" (»Das Massaker aller Gesandten«) eine mögliche Rache:

58 Vgl. z. B. Mühlhahn: China und der westliche Imperialismus, S. 24; Dabringhaus: Die Boxer. Motivation, Unterstützung und Mobilisierung, S. 62 f; Vogelsang: Geschichte Chinas, S. $481 \mathrm{f}$.

59 Vgl. Vogelsang: Geschichte Chinas, S. 482.

60 Vgl. Fögl d'Engiadina, 20. Oktober 1900, vgl. zum Thema auch Dominik Nowak: Der Tod des deutschen Gesandten Clemens von Ketteler, in: Kolonialkrieg in China. Die Niederschlagung der Boxerbewegung 1900-1901, hg. von Mechthild Leutner und Klaus Mühlhahn, Berlin: Christoph Links, 2007, S. 111-117.

61

Vgl. Gasetta Romontscha, 12. Juli 1900; Fögl d’Engiadina, 2. Juni 1900, 26. Januar 1901. 
Tenor in usit internazional vegnan ils salvadis ne negers, che mazzan Europeers, castiai cun bombardar ed intschendrar gl'entir liug dils assassins, e tier in pievel, che ei schi loschs sin sia veglia civilisaziun sco ils Chinès, e pudeva perquei renconoscher sias scandalusas ovras, sa il castitg buca curdar ora pli bass. La Gasetta de Cologna, l'emprema gasetta liberala della Germania, cusseglia per quei de far giustia culs Chinès cun bombardar ed intschendrar lur fortificada capitala e residenza de $1 \frac{1}{12}$ milliun habitonts. ${ }^{62}$

Gemäß internationalem Brauch werden die Wilden oder Neger, die Europäer töten, mit der Bombardierung und Niederbrennung der ganzen Wohnorte der Mörder bestraft, und bei einem Volk, das so stolz auf seine alte Zivilisation ist wie die Chinesen und deswegen seine skandalösen Taten ermessen konnte, kann die Strafe keinesfalls kleiner ausfallen. Die Kölner Zeitung, die erste liberale Zeitung Deutschlands, rät deswegen zu Gerechtigkeit gegenüber den Chinesen, indem ihre befestigte Hauptstadt, der Wohnsitz von $1 \frac{1 / 2}{2}$ Millionen Einwohnern, bombardiert und niedergebrannt werde.

Zwar mutmaßt die GR im gleichen Artikel auch über mögliche Gründe der Boxerinnen für ihren Aufstand, darunter die innere Politik und Intrigen der Kaiserinwitwe Cixi 慈禧 (1835-1908), die europäische Einmischung in chinesische Staatsangelegenheiten oder die Zerstörung des Soziallebens der Boxer*innen durch den Bau der Eisenbahnen. Ein Jahr später erkennt die GR sogar einen gewissen Egoismus der fremden Nationalitäten an, ${ }^{63}$ aber keinesfalls möchte sie dadurch $»$ ils giavels melens" (»die gelben Teufel«), das "pievel barbaric e crudeivel» (»das barbarische und grausame Volk«) verteidigen, diese »bestiala banda chinesa (»bestialische chinesische Bande«), ${ }^{64}$ die Tausende von Christ*innen Stück für Stück und mit größter Grausamkeit massakriere und enthaupte. ${ }^{65}$ Aus dieser Perspektive ist die GR recht froh, als endlich der Feldmarschall Alfred von Waldersee (1832-1904) mit seinen Truppen gegen Beijing zieht, und dann, nachdem »il celestial [...] imperi« (»das himmlische Reich«) zum Opfer Europas geworden, vor allem durch die neuen Strafbestimmungen des sogenannten Boxerprotokolls, eine "splendida parada militera« (»prachtvolle Militärparade«) hält. ${ }^{66}$

Wie die GR nennt am 25. August 1900 auch das FE einige Gründe für den Ausbruch des Boxeraufstandes - erstens die Eisenbahnlinien, die das traditionelle Geschäft des Warentransports mit kleinen Schiffen zerstört und viel Arbeitslosigkeit

63 Vgl. Gasetta Romontscha, 3. Januar 1901.

64 Gasetta Romontscha, 13. September 1900, vgl. auch 23. August, 4. Oktober 1900.

65 Vgl. auch Gasetta Romontscha, 23. Januar 1901. 
und Hunger erzeugt hätten, zweitens (in der Ausgabe vom 23. März 1901) die Revolte gegen die Qing-Dynastie und drittens, so nicht von der GR erwähnt, die christliche Missionsarbeit:

[Las missiuns cristiaunas] dvantettan nels ultims ans bel e bain impertinentas e molestas. Aviand agieu discrets resultats, a que chi pera, cumanzettan surtuot ils preirs cattolics a smancher l'axioma del cristianismo, chi ais, u dovess esser, la toleranza, l'amur vers il prossem. Els volettan dominer, regner, suainter lur veglia e nefasta üsaunza. La conseguenza and füt, cha la granda massa del pövel, indifferenta in materias religiusas, ils pigliet in ödi tel, ch'el laschet cha'ls Boxers als dettan addöss ed extermineschan eir ils Chinais convertieus. Que ais da dubiter, cha quaista terribla lezcha possa instruir ils missiunaris del avvegnir. ${ }^{67}$

[Die christlichen Missionen] wurden in den letzten Jahren recht unverschämt und lästig. Nach dem Erreichen bescheidener Resultate, so wie es scheint, begannen vor allem die katholischen Priester das Axiom des Christentums zu vergessen, das Toleranz, Nächstenliebe ist oder sein sollte. Sie wollten dominieren, herrschen, gemäß ihrem alten und unheilvollen Brauch. Die Konsequenz war, dass die große Mehrheit des Volkes, gleichgültig in religiösen Fragen, gegen diese Hass entwickelte und es akzeptierte, wenn die Boxer Missionare angriffen und auch die konvertierten Chinesen ausrotteten. Es ist zu bezweifeln, dass diese schreckliche Warnung die Missionare in Zukunft belehren kann.

Die Kritik des FE gegen die Missionar*innen in China ist radikal - in der Ausgabe vom 14. Juli 1900 werden sie zusätzlich als »esters [chi] as mettaivan sur las ledschas del pajais [chi] as crajaivan in dret da fer bger, memma bger, be a lur möd « (»Fremde, die sich über die Gesetze des Landes stellten, die sich im Recht glaubten, viel zu tun, zu viel, und nur auf ihre Art «) bezeichnet, ${ }^{68}$ womit auch ihre Exterritorialität verurteilt wird. Insgesamt sieht die Kritik für die Mission, wie im oberen Zitat gesehen, keine Zukunft, da der Evangelisierungstrieb selbst auf Dogmen beruhe. ${ }^{69}$ Die Soldaten der Alliierten, die auf dem Weg nach und in Beijing wüteten, ${ }^{70}$ werden vom FE als Barbaren bezeichnet, sarkastisch zudem die Gesamtgewalt des

69 Eine leise Kritik an der Mission in der katholischen Surselva selbst ist zu sehen in: La Quotidiana, 6. September 2006.

Fögl d'Engiadina, 25. August 1900.

Fögl d'Engiadina, 14. Juli 1900.

Vgl. Fögl d'Engiadina, 24. November 1900. 
Feldzugs nach Beijing als christliche Zivilisation. ${ }^{71}$ Was nun aber überraschend ist die Kritik des $F E$ gegen den Imperialismus war bereits bei der Kommentierung des Französisch-Chinesischen-Kriegs (1884-1885) ausgeprägt - ist die zusätzliche Empathie für die mordenden ${ }^{72}$ Boxer, eine »bunte Mischung aus fahrendem Volk und Handwerkern: Hausierer und Rikshakulis, Sänftenträger, Kanalschiffer, Lederarbeiter, Messerschleifer und Barbiere, außerdem entlassene Soldaten und Salzschmuggler $«{ }^{73}$ Die Empathie des FE mag die Nebenwirkung einer Idee gewesen sein, die auch für die rätoromanische Kultur von Bedeutung ist: dass Kulturen autonom und souverän bleiben müssten, oder anders formuliert: keine Kultur das Recht bekommen sollte, eine andere, weniger mächtige zu unterdrücken. »Ils Boxers vöglian bainschi cha la China saja per ils Chinais e taunt inavaunt nun as so guera che dir in contrari« (»Die Boxer wollen wohl ein China für die Chinesen, und insofern weiß man gar nicht, was dagegen zu sagen wäre«), heißt es an einer Stelle, ${ }^{74}$ woanders: »Ma eir ils Chinais peran dad esser gnieus stüffis d'as lascher piglier our d'maun lur roba, ed els volessan, bain memma tard, tenter da resister all'invasiun dels esters." (»Aber auch die Chinesen scheinen es satt zu haben, sich aus den Händen ihre Sachen stehlen zu lassen, und sie wollen versuchen, wohl zu spät, gegen die Invasion der Fremden Widerstand zu leisten. $)^{75}$

\section{Mukden vor der Schlacht und A. Volkart-Christoffel}

Bis zur Gründung der Volksrepublik 1949 änderten sich die Positionen der GR und des FE gegenüber China nicht. Die GR beklagte in der Regel die Tötung von Missionar*innen und das FE die Angriffe gegen China. Als Japan 1904 in der Mandschurei Russland angriff, konnte dieses Ereignis als Krieg zwischen Europa und Asien, dem Westen und Osten, inszeniert werden. Mit großartiger Dramaturgie hat die GR ihre Leser*innen, auch mithilfe der Übertragung gewisser Stellen aus dem Reisebericht $A$ travers la Mandchourie. Notes de voyage des Missionars Péter Vay von Vaya und Luskod (1863-1948), ${ }^{76}$ auf die Schlacht bei Mukden (heute: Shenyang) eingestimmt. In der Ausgabe vom 18. Februar 1904 wurde zur Übersicht des Kampfortes eine große Landkarte abgebildet und am 20. Oktober 1904 die Stadt Mukden - im Zustand vor ihrer baldigen Zerstörung - vorgestellt. Wir sehen die symmetrische

71 Vgl. Fögl d’Engiadina, 1. September 1900, 5. Januar 1901.

72 Vgl. Fögl d'Engiadina, 23. Juni 1900.

73 Spence: Chinas Weg in die Moderne, S. 290.

74 Fögl d'Engiadina, 23. Juni 1900.

75 Fögl d'Engiadina, 16. Juni 1900.

76 Vgl. Péter Graf Vay von Vaya und Luskod: A travers la Mandchourie. Notes de voyage, in: $R e$ vue des Deux Mondes, Cinquième periode, Bd. 23, Nr. 1 (1. September 1904), S. 132-163. Ähnliche Passagen wie die Mukden-Beschreibung in der GS sind auch zu finden in: Péter Graf Vay von Vaya und Luskod: Empires and Emperors of Russia, China, Korea, and Japan. Notes and Recollections, New York: E. P. Dutton, 1906, S. 88-108. 
Anordnung der Straßen, durch »las pli intressantas figuras de tiers e plontas fantasticas" (»die interessantesten Figuren von fantastischen Tieren und Pflanzen«) geschmückte Fassaden der Häuser, die in allen Farben glänzen, sodann buddhistische und konfuzianische Tempel mit gelben Ziegelsteinen, eine Menge von Leuten aus allen Ländern, viele Händler und von diesen viele zu Ross, schließlich den Friedhof der alten Herrscher, mit einem Triumphbogen von »stravagantas dimensiuns" (»unglaublichen Dimensionen«), am Rande der Wege Steinfiguren von Elefanten, Kamelen, Drachen und Giganten und zuletzt die Russen, wie sie das Archiv des Imperiums, alle alten Dokumente und Manuskripte, »acts de fetg grond interess per la historia della China" (»Akten von sehr großem Interesse für die Geschichte Chinas«), stehlen und nach St. Petersburg bringen. ${ }^{77}$

Ansonsten haben weder die $G R$ noch das $F E$ ausführlicher über die republikanischen Rebellionen, das Ende der Qing-Dynastie 1911/12 oder die Bürgerkriege zwischen der Guomindang und den Kommunisten berichtet - wobei der Kommunismus als System der Gleichschaltung in allen rätoromanischen Zeitungen abgelehnt wurde. $^{78}$ Immerhin meinte das FE zum Ende der Kaiserzeit:

Nella lontauna Asia s'ho in quaist an accomplieu ün dels pü grandius evenimaints dell'istoria universela: L'imperatur della China [...] ho svess proclamo la republica. [...] Vzand la partida persa, ho la dinastia Mandschu savieu as retrer cun dignited ed eleganza dal trun [...]. Lactuel imperatur, ün infaunt da quatter ans, nun averò piglio la chosa uschè a cour. ${ }^{79}$

Im fernen China hat sich dieses Jahr eines der grandiosesten Ereignisse der allgemeinen Geschichte ereignet: Der Herrscher Chinas [...] hat selber die Republik proklamiert. [...] Die Mandschu-Dynastie hat sich, die Niederlage kommen sehend, mit Würde und Eleganz vom Thron zurückzuziehen gewusst. [...] Der aktuelle Herrscher, ein Kind von vier Jahren, wird sich die Sache nicht so zu Herzen genommen haben.

Vermutlich, sei hinzugefügt, wusste Puyi 溥儀 (1906-1967) auch nicht so recht, wie ihm geschah, als Zhang Xun 張動 (1854-1923), ein fanatischer Qing-Anhänger, und dessen Truppen ihn 1917 in Beijing wieder für ein paar Tage als Kaiser einsetzten ${ }^{80}$ die Japaner ${ }^{\star}$ innen dann 1932 als Kaiser von Mandschukuo. ${ }^{81}$

78 Vgl. z. B. La Casa Paterna, 1927, Nr. 45.

79 Fögl d'Engiadina, 24. Februar 1912.

80 Vgl. Spence: Chinas Weg in die Moderne, S. $352 \mathrm{f}$.

81 Vgl. Gasetta Romontscha, 8. März 1934. 
In den 1920er Jahren jedoch entstanden zwei weitere großformatige rätoromanische Zeitungen, 1920 La Casa Paterna (1920-1996, ab 1974 Fusion mit La Pùnt) für den protestantischen Teil der Surselva, des Tumleastga (Domleschg) und des Val Schons (Schams) sowie 1922 die Gazetta Ladina (1922-1940, 1941-1996 dann Fögl Ladin) im Unterengadin. Beim Fögl Ladin fällt eine gewisse unkritische Heroisierung des Chiang Kai-shek 蔣介石 (1887-1975) ins Auge, ${ }^{82}$ besonders in den frühen 1940er Jahren, was vielleicht einer Identifizierung mit der eigenen Situation entsprach. Falls die Engadiner ${ }^{\star}$ innen gegen die Faschistinnen hätten kämpfen müssen, dann wunschgemäß mit derselben Ausdauer wie Chiang Kai-shek und seine Truppen gegen die Japaner*innen und Kommunist*innen. Zum Zweiten Japanisch-Chinesischen Krieg (1937-1945) berichtete dann ausführlich La Casa Pater$n a$, die in diesem Fall eine ähnliche Rolle spielte wie wenige Jahre zuvor das $F E$ bei der Kommentierung des Boxerkrieges. Lügen zur Rechtfertigung des Einmarsches, etwa die japanische Minderheit in China beschützen zu müssen oder für Ordnung zu sorgen, werden genauso verurteilt wie die Annexion der Mandschurei samt nachfolgender Bildung eines Marionettenstaates, die unbeschreibliche Grausamkeit der japanischen Angriffe, das illegale Vorgehen und Brechen internationalen Rechts, die Ausweitung der Kriege in Länder Südostasiens - hauptsächlich mit dem Ziel, die westliche Waffenlieferungen an China zu unterbrechen oder an Öl zu kommen und schließlich die Bildung einer faschistischen Achse zwischen Rom, Berlin und Tokio sowie das verzerrte Bild von Japan als Land der Zivilisation und des Fortschritts. ${ }^{83}$ "Pauca honur ad ina tiara, che vul esser pli civilisada ch'autras (»Wenig Ehre für ein Land, das zivilisierter sein möchte als andere«) ${ }^{84}$

Redaktor der Casa Paterna von 1924 bis 1947 war Hans Erni (1867-1961). ${ }^{85}$ Er ist heute vor allem als Komponist rätoromanischer Chorlieder bekannt ${ }^{86}$ und scheint einen guten Verstand und eine feine Intuition für politische Vorgänge gehabt zu haben. »Il mund semeglia oz ina gronda casa de stuornadira« (»Die Welt ähnelt heute einem großen Irrenhaus «) lautet ein politischer Kommentar, den er - abgeändert - öfters verwendete. ${ }^{87}$ Ansporn für Hans Ernis ausführlichere Berichterstattung über den Zweiten Japanisch-Chinesischen Krieg mag A. Volkart-Christoffel gewe-

Vgl. Fögl Ladin, 11. Oktober, 6. Dezember 1940, 12. Juni 1942, 20. Juli 1945. Chiang Kai-shek war nicht weniger grausam als die Führer anderer Parteien. 1927 zum Beispiel erschossen seine Truppen Tausende von Kommunist ${ }^{\star}$ innen und Gewerkschafter ${ }^{\star}$ innen in Shanghai, vgl: Vogelsang: Geschichte Chinas, S. $518 \mathrm{f}$.

83 Vgl. z. B. La Casa Paterna, 1931, Nr. 39 und 47; 1932, Nr. 2; 1933, Nr. 3, 4, 6, 9 und 23; 1935, Nr. 7, 26 und 46; 1936, Nr. 4 und 23; 1937, Nr. 43; 1939, Nr. 27 und 33; 1941, Nr. 44 und 51.

84 La Casa Paterna, 1941, Nr. 44.

85 Vgl. Cantieni: Geschichte der rätoromanischen Presse in Graubünden, S. 35.

86 Vgl. Gallus Pfister: Vier romanische Komponisten, in: Bedeutende Bündner aus fünf Jahrhunderten, Chur: Calven, 1970, Bd. 2, S. 391-414, hier S. 395-399.

87 Vgl. La Casa Paterna, 1936, Nr. 15; 1941, Nr. 28. Hinsichtlich des Faschismus in Deutschland kam er 1933 (La Casa Paterna, 1933, Nr. 8) zur Einschätzung: »In tal regiment despotic ha mai existiu entochen cheu en Germania« (»Ein so despotisches Regime hat bis jetzt noch nie in Deutschland existiert«). 
sen sein, ein Korrespondent, der zwischen 1934 und 1939 in mehr als zwei Dutzend Artikeln in Sursilvan für die Casa Paterna aus Shanghai berichtete. Seine Texte sind oft von hoher sprachlicher Qualität und vermittelten erstmals einer rätoromanischen Öffentlichkeit wirkliche chinesische Alltagsszenen.

Noch unklar ist zurzeit das Bild des A. Volkart-Christoffel. ${ }^{88}$ Aus den Reportagen kann abgeleitet werden, dass es sich um einen Mann handelt, der eine Rätoromanin namens Christoffe ${ }^{89}$ heiratete. Er stammte entweder selbst aus den Bündner Bergen oder war mit diesen verbunden, ${ }^{90}$ lebte zwischen 1934 und 1939 in China, hauptsächlich in Shanghai - die Stadt war um 1936 Wohnsitz von über 200 Schweizer*innen, ferner auch Sitz des schweizerischen Generalkonsulats und der Botschaft ${ }^{91}{ }^{-}$, kannte Shanghai seit mindestens $1923^{92}$ und hatte 1908 auch erstmals Harbin in der Mandschurei besucht, wo er ein »stupent viver: vivondas ed buvrondas en abundonza ("prächtiges Leben: Nahrung und Getränke im Überfluss «) ${ }^{93}$ genoss. Ferner führte A. Volkart-Christoffel ein abenteuerliches Leben ohne Askese und scheint weder besonders religiös noch anti-religiös gedacht zu haben. Er lehnte das »brutal sistem communistic ed igl imperialissem japanes « (»brutale kommunistische System und den japanischen Imperialismus «) $\mathrm{ab}^{94}$ und wurde an einer Stelle als »in patriot svizzer de vera stampa (»ein Schweizer Patriot von wahrem Stempel «) bezeichnet, ${ }^{95}$ war demnach vermutlich Föderalist. Seine Texte zeigen eine deutliche Ablehnung dogmatischer Behauptungen und zugleich feinen Humor: »De criticar cun disprez ils eveniments politics en China essan nus pioniers culturals alvs buca legitimai, pertgei mumma Europa ha avunda da scuar avon l'atgna porta« (»Mit Verachtung die politischen Ereignisse zu kritisieren, sind wir weisse kulturelle Pioniere nicht legitimiert, denn Mutter Europa hat genügend vor ihrer eigenen Türe zu wischen «). ${ }^{96}$ Vor 1938 lebte A. Volkart-Christoffel mit seiner Familie in der Yu Yuen Road in Shanghai, zusammen mit einer Schreibmaschine und in Nachbarschaft zweier jun-

88 Silvia Gygax von der Volkart-Stiftung und Michael Rezzoli vom Stadtarchiv Winterthur ich bedanke mich herzlich für ihre Recherchen - fanden keine Spuren, weswegen A. Volkart höchstwahrscheinlich nicht direkt mit der Volkart-Familie in Winterthur, die mit ihrer Firma Volkart Brothers Agency eine international führende Stellung im Baumwollhandel einnahm und auch in Shanghai Geschäfte hatte, verbunden war. Auch mit Otto Volkart, der u. a. 1932 in Zernez über die Sowjetunion referierte, hatte A. Volkart wohl nichts zu tun. Vgl. Fögl d'Engiadina, 30. März, 1. Mai 1917, 2. Februar 1932.

89 Vgl. La Casa Paterna, 1937, Nr. 46; 1936, Nr. 6.

90 Vgl. La Casa Paterna, 1934, Nr. 15; 1937, Nr. 28.

91 Vgl. Konrad Specker: Aspekte der Beziehungen zwischen der Schweiz und China - eine historische Perspektive, in: Swiss-Chinese Chamber of Commerce Bulletin, Nr. 2, 2000, S. 30-57, hier S. 40.

92 Vgl. La Casa Paterna, 1934, Nr. 18.

93 Vgl. La Casa Paterna, 1935, Nr. 21.

94 La Casa Paterna, 1936, Nr. 15.

95 Vgl. La Casa Paterna, 1936, Nr. 3.

96 La Casa Paterna, 1937, Nr. 7. 
ger Engländer, die eine hohe Position im Finanzdepartement innehatten, ${ }^{97}$ weswegen er vermutlich zur reicheren Schicht Shanghais gehörte. In Nanjing hielt er sich von spätestens November 1937 bis gegen Ende Januar 1938 (Mitte Januar 1938 war er anscheinend noch in Nanjing, ${ }^{98}$ später im selben Monat in Shanghai) in deutscher Gesellschaft und Nachbarschaft des Hauses des Kommandanten Ku Chu Cheng (Chen Cheng 陳誠 [1897-1965]?) auf. Am 13. Dezember 1937, als die Portale der Stadt bereits abgeriegelt waren und das Massaker innerhalb der Stadt begann, transportierte A. Volkart-Christoffel »cun auters cumpogns« (»mit anderen Gefährten«) Reis in die Sicherheitszone - in den folgenden Tagen gegen 8000 Säcke $^{99}$ - sowie in ein Spital mit verwundeten chinesischen Soldaten. ${ }^{100}$ Gegen 23:30 Uhr desselben Tages kam er erstmals in Kontakt mit japanischen Besetzern. ${ }^{101}$ Erstaunlicherweise aber wird er weder in den Tagebüchern von John Rabe (1882-1950) erwähnt ${ }^{102}$ noch in der bei Rabe zu findenden Liste der nicht-japanischen Ausländer*innen, die sich am 21. Dezember 1937 in Nanjing aufhielten, ${ }^{103}$ noch in Iris Changs Buch The Rape of Nanking (1997). Am 28. Dezember 1937 hat A. Volkart-Christoffel jedoch, nach einem Vergleich der Beschreibungen abgeleitet, zusammen mit Christian Kröger die Umgebung von Nanjing besucht (siehe Ziffer 7). ${ }^{104}$ Daraus könnten wir zurzeit, ohne Vorhandensein weiterer Informationen, Folgendes folgern: Entweder befanden sich in Nanjing mehr nicht-japanische Ausländerinnen, als bei Rabe und Kröger erwähnt sind, oder A. Volkart-Christoffel verwendete mehrere Namen, oder aber er war im Dezember 1937 gar nicht in Nanjing und erfand seine eigenen Erlebnisse, indem er Berichte von Anderen übernahm und leicht abänderte. Nähmen wir den letzten Punkt an, was keinesfalls klar ist, dann hätte A. Volkart-Christoffel wohl eine diplomatische Tätigkeit ausgeübt, mit der er an solche Berichte gekommen wäre. Denkbar wäre auch, dass er - wie John Rabe für Siemens \& Halske oder Christian Kröger für Carlowitz \& Co. - bei einer größeren Firma (Gebrüder Volkart?) angestellt war, im Bereich des Spitalwesens oder sogar, auch dies kann nicht ausgeschlossen werden, für das Missionswesen arbeitete. Viele seiner Artikel sind bildreich, humorvoll, sozialkritisch und scharf in der Betrachtung gesellschaftlicher Szenen,

Vgl. La Casa Paterna, 1934, Nr. 23; 1938, Nr. 13.

Vgl. La Casa Paterna, 1938, Nr. 14.

Vgl. La Casa Paterna, 1938, Nr. 16.

Vgl. La Casa Paterna, 1938, Nr. 16; Nr. 15 supplement.

Vgl. La Casa Paterna, 1938, Nr. 14.

John Rabe war Geschäftsführer bei Siemens \& Halske in Nanjing, NSDAP-Mitglied und Vorsitzender der Sicherheitszone, durch die über 200'000 Bewohner*innen Nanjings gerettet wurden.

03 Vgl. John Rabe: The Good Man of Nanking. The Diaries of John Rabe, hg. von Erwin Wickert und übers. von John E. Woods, New York: Vintage Books, 2000, S. 272.

Die am 13. Januar 1938 verfasste Beschreibung von Christian Kröger, Mitarbeiter bei Carlowitz \& Co, Gefährte von John Rabe und wie dieser NSDAP-Mitglied, ist zu finden ebd., S. 143-145, die beinahe identische Beschreibung von A. Volkart-Christoffel in: La Casa Paterna, 1938, Nr. 16. 
weswegen sie manchmal an Erzählungen von B. Traven erinnern mögen. Er scheint sehr mutig gelebt zu haben, erlebte Bombardierungen und war Zeuge von grauenhaften Bildern und Zeiten, die man, so meinte er, sein Leben lang nicht mehr vergessen könne. ${ }^{105}$

\section{Terror in Nanjing, Bomben und Rikschas in Shanghai}

Die chinesischen Themen der Texte von A. Volkart-Christoffel, zu denen alle Leser*innen der Casa Paterna Zugang bekamen, sind, chronologisch geordnet und vereinfacht zusammengefasst, folgende: die Kriegswirren der großen Länder wie China und Russland; das Leben der Rikscha-Fahrer in Shanghai; der kommunistische Terror; Erlebnisse in Harbin 1908; das Bauen einer Straße; das Attentat gegen Wang Jingwei 汪精衛 (1883-1944); gefangene kommunistische Rebellen; He Long 賀龍 (1896-1969) und militärische Konflikte; die Geiselnahme eines Missionars durch Kommunisten; verwirrte Chines*innen, die aus Russland zurückkehrten; Zhang Xueliangs 張學良 (1901-2001) Entführung von Chiang Kai-shek; ${ }^{106}$ Versicherungsbetrug in Shanghai; Telefone in Shanghai; die Bombardierung von Shanghai aus der Luft; chaotische Fluchtszenen aus Shanghai; Frauen im Krieg; Anschläge gegen Journalisten; Berichte zu Neuseeland und Tahiti; die Besetzung von Nanjing; Massaker und Vergewaltigungen in Nanjing und Umgebung; Spitalszenen aus Nanjing; die Zerstörung von Guangzhou; die Angst der Chines*innen vor der Mondfinsternis und der Glaube an den Himmelshund (Tiangou 天狗) sowie Berichte einer Bootsreise nach Taiwan. ${ }^{107}$

Die "gis da terrur e panica de Nanking« (»Tage des Terrors und der Panik von Nanjing «), ${ }^{108}$ die ihn, wie überhaupt das Vorgehen der Japaner, an »ils temps dellas conquistas d'in Chengis Khan e la sanguinusa rebelliun de Taiping « (»die Zeiten der Eroberungen eines Dschingis Khan und die blutige Rebellion der Taiping «) gemahnten, ${ }^{109}$ hat A. Volkart-Christoffel eindrücklich beschrieben. »Attacas, che daventan pli e pli furiusas, semnan mort e sgrischur» (»Attacken, die nach und nach rasender werden, säen Tod und Schrecken «). ${ }^{110}$ "Las vias ein curcladas da morts e blessai e da material d'uiara de scadina specia. Confusiun terribla! Il marcau sumeglia in uffiern« (»Die Straßen sind zugedeckt mit Toten, Verwundeten und Kriegsmaterial al-

108 La Casa Paterna, 1938, Nr. 16.

109 La Casa Paterna, 1939, Nr. 23; vgl. auch: Rabe The Good Man of Nanking, S. 148.

110 La Casa Paterna, 1938, Nr. 14. 
ler Art. Schreckliches Durcheinander! Die Stadt gleicht einer Hölle«). ${ }^{111}$ Auch in der Umgebung von Nanjing, unter anderem in »Tsichia-shan", dem Hügel Qixia shan 栖霞山, den er am 28. Dezember 1937 zusammen mit Christian Kröger besuchte, herrscht Schrecken:

Suenter la via d'automobils schain cadavers de buffels, cavals e mels, magliai per part da tgauns ed utschleglia. [...] Giuvens mattatschs vegnan fusilai en massa senza misericordia, giuvnas vegnan maltractadas e violadas, e schuldada eivra ha in plascher infernal da blessar u mazzar tut quei che plai buc ad ella. ${ }^{112}$

Entlang der Straße liegen Kadaver von Büffeln, Pferden und Mauleseln, zum Teil gefressen von Hunden und Vögeln. [...] Junge Burschen werden in Massen erschossen, erbarmungslos, junge Frauen misshandelt und vergewaltigt, und die Soldaten scheinen eine höllische Freude zu haben, all das, was ihnen nicht gefällt, zu verwunden oder zu töten.

Zahlreiche weitere Szenen aus Nanjing wurden durch die Casa Paterna vorgestellt, das Demolieren der Häuser und Tempel, das systematische Stehlen und Vernichten von Nahrung zur Erzeugung von Hungersnot - »ils pli paupers dils paupers vegnan privai de lur ris, da tuttas provisiuns, da cozzas e vestgadira« (»die Ärmsten der Ärmsten werden ihres Reises beraubt, all ihrer Vorräte, ihrer Decken und Kleider «) - die schlechte Organisation des chinesischen Militärs und ihrer Verteidigung, samt frühzeitiger Flucht von Hauptverantwortlichen, besonders des Generals Tang Shengzhi 唐生智 (1889-1970), ${ }^{113}$ oder die Lage der Verwundeten in den Spitälern, denen gemäß japanischem Befehl ärztliche Hilfe untersagt war, sowie der Flüchtlinge in der Sicherheitszone in Shanghai, "26 camps [...] occupai mintgin da melli entochen 35000 fugitivs ( (»26 Lager [...] jedes besetzt mit tausend bis 35’000 Flüchtlingen «). ${ }^{114}$ Besonders eindrucksvoll fing Volkart-Christoffel akustische Phänomene ein. Nach der Niederlage der chinesischen Armee und bei der japanischen Übernahme Nanjings hätte sich gegen Mittag des 13. Dezember 1937 zuerst eine totale und angespannte Stille entwickelt. Aus dieser Stille heraus seien dann mit Angst alle Schrecken erwartet worden: »Entuorn miezgi regia in silenzi bunamein fantastic el marcau. Ils Chines sezuppan en las casas, tut spetga ils Japanes, charrivan buc."

111 Ebd.

112 La Casa Paterna, 1938, Nr. 16; vgl. auch Chang: The Rape of Nanking, S. $46 \mathrm{f}$.

113 La Casa Paterna, 1938, Nr. 14. Zur Kritik an Tang Shengzhi vgl. auch Rabe: The Good Man of Nanking, S. 39 und 65.

114 La Casa Paterna, 1938, Nr. 16. In den Tagebüchern von John Rabe wird zusätzlich das systematische Niederbrennen der Stadt beschrieben, dazu das wochenlange Verbot, die tausenden auf den Strassen und in Pfützen liegenden oder aufgehängten, aufgenagelten Leichen zu bestatten oder zu verbrennen. Vgl. z. B. Rabe: The Good Man of Nanking, S. 84, 89 und 103. 
(»Um Mittag herrscht eine beinahe phantastische Stille in der Stadt. Die Chinesen verstecken sich in den Häusern, alle erwarten die Japaner, die nicht eintreffen. « $)^{115}$

Nicht weniger eindrücklich sind die akustischen und sensorischen Beschreibungen des japanischen Luftangriffs auf Shanghai im Herbst 1937.

Gest el mumen che jeu scrivel questas lingias, sgolan maschinas diabolicas sur nossas avdonzas. Ils canuns dils bastiments de grond caliber ramplunan, ed allas canunadas seunescha il fracass dils canuns che protegian d'attacas ord l'aria, de mitraglias etc. Ed aschi gleiti che la canera infernala tschessa empau, resunan las sirenas d'ambulanza ed il tibar dils pompiers. E pertgei quei? Negin ei segirs della veta. Mintga mumen sa ina bomba sturnir el. [...] Sur nus in tschiel stgir-blau, ina miglia da nus ina canunada infernala, sis, siat ni otg bombas schulan tras l'aria, crodan cun immens fracass a tiara e fan tremblar las casas. [...] Hui...uh! Co la casa trembla, ils veders dellas fenestras scadeinan, tuts tgauns della vischinonza uorlan; tgei duei quei significar?!116

Eben im Moment, wo ich diese Zeilen schreibe, fliegen teuflische Maschinen über unsere Behausungen. Die Kanonen der großen Kriegsschiffe dröhnen, und auf die Kanonenschüsse folgt der Lärm jener Geschütze, die vor Luftangriffen schützen, von Kartätschen usw. Und sobald der höllische Lärm ein wenig nachlässt, erschallen die Sirenen der Krankenwagen und das Heulen der Feuerwehren. Warum das? Keiner ist sich seines Lebens sicher. Jeden Moment kann ihn eine Bombe totschlagen. [...] Über uns ein dunkelblauer Himmel, eine Meile von uns ein schreckliches Geschützfeuer, sechs, sieben oder acht Bomben fliegen durch die Luft, fallen mit unermesslichem Lärm zur Erde und lassen die Häuser erzittern. [...] Hui...uh! Wie das Haus zittert, die Glasscheiben der Fenster rütteln, alle Hunde der Nachbarschaft heulen; was soll das bedeuten?!

Betrachten wir, bevor wir zur Volksrepublik kommen, noch kurz eine nicht ohne Humor geschilderte Szene aus dem Shanghai vor dem japanischen Angriff, genauer gesagt: das Leben der Rikscha-Fahrer. Ununterbrochen »cuoran quels paupers legionars chines pil grond marcau entuorn en las pli grondas ferdaglias, en caliras de 40 grads, en plievgias e vents« (»rennen diese armen chinesischen Legionäre in der Stadt herum, bei größter Kälte, bei Hitze von 40 Grad, bei Regen und Wind «). Sie schuften sich ab, 12 oder mehr Stunden am Tag, aber »70 entochen 80 centims a gi sto il pauper Lazarus surdar al patrun« (»70 bis 80 Rappen täglich muss der arme

116 La Casa Paterna, 1937, Nr. 46, 51 und 48. 
Lazarus seinem Chef abgeben«). Die wenigen Dollars, die sie verdienen, »drovan els per vestgadira, carta d'inscripziun e per dunsena: ina tassa pleina macaruns, preparai da frina de fava en aua tschuffa, $u$ ina scadiola ris cotg, cun empau verdura" (»brauchen sie für Kleider, für die Inskriptionskarte und für Kost: eine Tasse mit Makkaroni, zubereitet aus Bohnenmehl in schmutzigem Wasser, oder eine Tasse gekochten Reis mit ein wenig Gemüse «). ${ }^{117}$ Nicht alleine eine Person müssen die Rikscha-Fahrer durch die Straßen ziehen, sondern »duas, beinduras treis Chinesas u in auter compatriot, che pren aunc siu letg, ina maschina de cuser u pliras coffras, sacs, tassas de bambus sin in viadi de pliras meglias en in liug al confin dil marcau" (»Zwei, bisweilen drei Chinesinnen oder einen anderen Landsmann, der noch sein Bett, eine Nähmaschine oder mehrere Koffer, Säcke, Bambuskörbe mitnimmt, auf eine Reise von mehreren Meilen zu einem Ort am Rande der Stadt«). ${ }^{118}$

\section{8. Über Tibet}

Die Ausrufung der Volksrepublik China am 1. Oktober 1949 wird in der Gasetta Romontscha trocken und nur auf der letzten Seite in drei Sätzen mitgeteilt, ${ }^{119}$ im Fögl Ladin und der Casa Paterna wird vom Ereignis nicht berichtet. Anna Maria Cantieni verwies, wie auch Robert $\mathrm{H}$. Billigmeier, auf den »ausgeprägten regionalen Charakter der romanischen Presse«, die nicht »über den Stellenwert der Zusatzpresse« hinauskäme. ${ }^{120}$ Diese Behauptung stimmt einigermaßen für die rätoromanischen Zeitungen ab 1950 und klar ab den 1970er Jahren, aber keinesfalls, wie am Beispiel von China gezeigt wurde, für diejenigen zwischen 1830 und 1950, ${ }^{121}$ die ausführlich über Ereignisse im Ausland informierten, sehr ausführlich sogar. ${ }^{122}$ Redaktoren wie Gian Fadri Caderas vom Fögl d'Engiadina, der sechzehn Jahre im Hotel Bernina in Samedan wohnte, ${ }^{123}$ veröffentlichten nicht nur regelmäßig Berichte zur politischen Lage in China, sie waren durch die Lektüre anderer Zeitungen auch gut darüber informiert. Mehr als 20 Quellen sind für Berichte zu China im FE angegeben, darunter auffallend viele englische Zeitungen wie Standard, Times, Daily Grafic, Manchester Guardian, Univers, Daily Express oder Globe, die wegen der englischen Gäste

117 La Casa Paterna, 1934, Nr. 17.

118 La Casa Paterna, 1934, Nr. 18.

119 Vgl. Gasetta Romontscha, 6. Oktober 1949.

120 Cantieni: Geschichte der rätoromanischen Presse, S. 8 f.; vgl. auch Robert H. Billigmeier: Land und Volk der Rätoromanen. Eine Kultur- und Sprachgeschichte, Frauenfeld: Huber, 1983, S. 415.

121 Abgesehen von den erwähnten Titeln gilt das auch für Il Patriot (1874-1882), L'Engiadinais (1876-1882), Il Progress (1881-1883) oder Il Sursilvan (1883-1891).

122 Hie und da gab es Einwände gegen die Berichte aus China. Vgl. z. B. Fögl d'Engiadina, 21. Oktober 1911; Gazetta Ladina, 1926, Nr. 8; Il Glogn, 1928, S. 91.

123 Vgl. Maxfield: Studies in Modern Romansh Poetry in the Engadine, S. 69. 
in größeren Hotels des Engadins auflagen. ${ }^{124}$ Als aber nach dem Zweiten Weltkrieg das (deutschsprachige) Radio zur Verbreitung kam, später das (deutschsprachige) Fernsehen, fiel der internationale Charakter der rätoromanischen Zeitungen in sich zusammen. Hie und da wurden noch die Angriffsversuche der Kommunist*innen auf Taiwan zwischen 1954 und 1962 erwähnt, ihre Missbrauchsfälle gegen Missionar*innen und Andersdenkende, die Atombombe 1964 oder 1976 die Beisetzung von Mao Zedong 毛澤東 (1893-1976), viel mehr aber nicht. ${ }^{125}$

Zahlreich hingegen waren Berichte zu den Ereignissen in Tibet ab 1950. Diese veränderten die Position der liberalen und der protestantischen Zeitungen gegenüber China und seiner Politik und führten wie bei der katholischen Gasetta Romontscha zu einer negativen Beurteilung. ${ }^{26}$ Jenes China, das die Engadiner Zeitungen vom 19. Jahrhundert - vor allem beim Boxerkrieg - bis 1950 als Opfer des japanischen und europäisch-amerikanischen Imperialismus verteidigt hatten, führte sich nun gegen Tibet selbst wie eine Imperialmacht auf. ${ }^{127}$ China habe "smaccau cun forza brutala la voluntad dad in pievel che ha empruau da viver tenor sias mesiras, tradiziuns e sia religiun " (»mit brutaler Gewalt den Willen eines Volkes zerdrückt, das gemäß seiner Maße, Traditionen und seiner Religion zu leben versucht hätte«), ${ }^{128}$ und zwar »seguond la metoda da Hitler e dal Kreml in Ungaria " (»nach der Methode von Hitler und dem Kreml in Ungarn «). ${ }^{129}$ Der Calender Per mintga gi (1922-1981), um ein weiteres Beispiel zu nennen, bezeichnete das chinesisch-besetzte Tibet im Jahre 1965 als »egn sulet camp da conzentraztgùn - egna noscha parschùn« (»ein einziges Konzentrationslager - ein schlimmes Gefängnis«). ${ }^{130}$ Die Flucht des Dalai Lama (Tenzin Gyatso) nach Indien 1959 ermunterte Tausende seiner Landsleute zur Nachahmung, andere Fluchtgründe waren Gewalt oder eine 1960 durch die chi-

124 Vgl. z. B. Fögl d'Engiadina, 11. August und 6. Oktober 1894, 4. Mai und 2. November 1895, 8. Januar 1898, 20. Mai 1899, 23. Juni und 21 Juli 1900.

125 Vgl. z. B. Casa Paterna, 1950, Nr. 1, 8 und 9; 1954, Nr. 37, 45 und 49; 1955, Nr. 6, 7 und 9; 1958, Nr. 35 und 39; 1962, Nr. 27; Gasetta Romontscha, 26. September 1967, 14., 17. und 21. September sowie 12. Oktober 1976. Die Niederschlagung des Protestes beim Tian'anmen-Platz 1989 wurde leicht ausführlicher nur durch einen Bericht von Alice Wenzel-Simonett in der Casa Paterna, 1989, Nr. 25 präsentiert.

126 Die katholische Gasetta Romontscha nahm durch ihren Fokus auf das Missionswesen von Anfang an eine anti-chinesische Position ein.

127 Nebenbei bemerkt: Dies tat China immer, beispielsweise bei der Besetzung der Mongolei ab 1918, bis dann die Truppen des verrückten Roman von Ungern-Sternberg (1885-1921), der das Reich des Dschingis Khan - unter anderem durch die Inthronisierung eines Mitglieds der Mandschudynastie - wiederbeleben wollte, 1921 die Chinesen aus Ulaanbaatar vertrieben. Vgl. Sergei L. Kuzmin: Der blutige weiße Baron und die Fakten, in: Berndt Krauthoff/ Michael Haupt: Ich befehle! Kampf und Tragödie des Barons Ungern-Sternberg, hg. von Sergei L. Kuzmin, Kiel: Regin, 2011, S. 309-331, insb. S. 318, 323 f.; vgl. auch Ferdinand Ossendowski: Tiere, Menschen \& Götter, Erkrath: Strange, 2001, S. 193.

128 La Casa Paterna, 1959, Nr. 14.

129 Fögl Ladin, 9. Juni 1959; vgl. auch ebd., 2. Oktober 1959.

130 Calender Per mintga gi, 1965, S. 112. 
nesische Migration und die im Rahmen des >Großen Sprungs` verordnete Zwangskollektivierung verursachte Hungersnot. ${ }^{131} \mathrm{Da}$ sich durch die Flucht auch die Lage in den Nachbarländern verschlimmerte, ${ }^{132}$ gelangten erste Tibeter ${ }^{*}$ innen ab 1960 mit Hilfe von Privaten und Institutionen in die Schweiz. Im Juli 1963 beschloss die Bevölkerung von Samedan im Oberengadin, sozusagen dem Tibet der Schweiz, 36 Tibeter*innen aufzunehmen, die im November desselben Jahres eintrafen und zuerst in der Chesa Dosch wohnten. ${ }^{133}$ Sie wurden, wie sich Karchung Bhusetshang erinnerte, »da maniera hozindi incredibla « (»in einer heute unvorstellbaren Weise«) herzlich durch eine Rede des Gemeindepräsidenten und den Chor der Gemeindeschule begrüßt. ${ }^{134}$

Wie könnte der Zusammenhalt zwischen Rätoroman*innen und Tibeter*innen, der sich auch im Singen tibetischer Lieder durch Chöre, in der gemeinsamen Organisation tibetischer Veranstaltungen oder im Hochziehen tibetischer Fahnen an Schulhöfen zeigte, ${ }^{135}$ - zudem leben Tibeter ${ }^{\star}$ innen auch in der Surselva ${ }^{136}$ - erklärt werden? Mit Fragen zur historischen oder geopolitischen Legitimation der chinesischen Besetzung Tibets ${ }^{137}$ hatte er wenig $\mathrm{zu}$ tun, zumindest sind solche Fragen in rätoromanischen Periodika kaum anzutreffen, ebenso wenig mit der Religion. Für die liberale Mehrheit der Rätoroman*innen war weder die frühere monastische Theokratie in Tibet von Reiz noch die Welt der buddhistischen Gläubigen, »ün muond plain urazchuns, chi nu piglian ingüna fin« (»eine Welt voller Gebete, die kein Ende nehmen «). ${ }^{138}$ Der exoterische Buddhismus selbst wiederum wurde von frommen Christ ${ }^{*}$ innen als Form der Ketzerei ohnehin abgelehnt ${ }^{139}$ und der philo-

131 Vgl. Emil Wiederkehr: Hunger, Elend und Zwangsarbeit vertreiben die Tibeter aus ihrem Land, in: Die Leiden eines Volkes. Die Tragödie Tibets und der tibetischen Flüchtlinge, hg. von der Schweizer Tibethilfe Solothurn, Solothurn: Veritas, 1961, S. 175-196, hier S. 177. Zum 'Grossen Sprung` vgl. Vogelsang: Geschichte Chinas, S. 546-557.

132 Vgl. La Casa Paterna, 1962, Nr. 45; 1963, Nr. 5; Fögl Ladin, 28. März 1961, 15. März 1963; Calender Per mintga gi, 1965, S. 113.

133 Vgl. Fögl Ladin, 12. Juli 1963; RTR: Die zweite Heimat. Tibeter in Samedan, in: Balcun tort, 12.11.1978, www.rtr.ch/play/tv/il-balcun-tort/video/die-zweite-heimat-tibeter-in-samedan?i d=505669dc-fda4-4f6a-8237-024dcae6a307, 1:51-3:00 (Zugriff 14.08.2020); auch La Casa Paterna, 1963, Nr. 21; Fögl Ladin, 15. März 1963.

134 Fögl Ladin, 22. April 1988; Pema Lamdark in: Lukas Schenk: Tibet. Samedan. Eine Geschichte von Heimat und Flucht, Film, 2008, https://vimeo.com/256758058, 5:40-6:00 (Zugriff 09.08.2020); La Quotidiana, 26. März 2008.

135 Vgl. z. B. La Quotidiana, 19. März 2004, 13. März 2007; Fögl Ladin, 22. April 1988.

136 Vgl. z. B. La Quotidiana, 26. März 2008.

137 Vgl. dazu vor allem Marcus Hölzl: Tibet. Vom Imperium zur chinesischen Kolonie, Frankfurt am Main: Peter Lang, 2009 (Politik und Demokratie, Bd. 16).

138 Vgl. RTR: Die zweite Heimat. Tibeter in Samedan, www.rtr.ch/play/tv/il-balcun-tort/video/ die-zweite-heimat-tibeter-in-samedan?id=505669dc-fda4-4f6a-8237-024dcae6a307, 3:54-3:58 (Zugriff 14.08.2020).

139 Vgl. Il Pelegrin, 1923, S. 31; Fögl d’Engiadina, 20. April 1901. 
sophische sehr selten in Zeitungen und Zeitschriften behandelt. ${ }^{140}$ Einzig in einem Exemplar der Dumengia saira von 1903, einer Beilage des Fögl d'Engiadina, befindet sich eine längere Ausführung zum Buddhismus, die allerdings mit der Erwähnung des Nicht-Seins als Ziel eher an die metaphysische Philosophie eines Philipp Mainländer (1841-1876) erinnert, denn an den Mahayana-Buddhismus mit seinem Nichts jenseits von Definitionen als Folge totaler Urteilsenthaltung.

Il buddismo ho ün profuond sentimaint per la sofferenza e la misiergia del muond, contain bgera misericordia e compassiun, ma nun ais in cas da's adozer surour il plaunt e la lamentaziun. Il muond ais in sieus ögls del tuot pervers, la vit' üna maledicziun ed ün pais ed ün nun po s'imaginer ün pü grand dalet cu quel, da pudair morir e's dissolver nel grand ünguotta, chi ais sieu principi e sia fin. Quels chi tiers ils buddists passan per ils pü pietus tscherchan da créer quaist stedi fingiò in quaista vita: per quaunt fattibel stan els cò sainza niaunchas smuanter - be na avair da penser, be na stovair s'occuper cun qualchosa, tranquillited, immersiun in ün sul stroliger, dissoluziun dellorma nella nirvana, il grand ünguotta $[\ldots] .^{141}$

Der Buddhismus hat ein tiefes Bewusstsein für das Leiden und das Elend der Welt, auch viel Gefühl für Mitleid und Erbarmen, ist aber nicht in der Lage, sich über das Klagen und Lamentieren zu erheben. Die Welt ist in seinen Augen völlig verderbt, das Leben ein Fluch und eine Bürde, und man kann sich keine größere Freude vorstellen als jene, sterben zu können und sich im großen Nichts aufzulösen, das deren Prinzip und Ende ist. Jene unter den Buddhisten, die als Frommste gelten, versuchen diesen Zustand bereits in diesem Leben zu kreieren: Tunlich stehen sie da, ohne sich nur einmal zu bewegen - nur nicht etwas zu denken haben, nur nicht sich mit irgendeiner Sache beschäftigen müssen, Stille, Eintauchen in eine unheimliche Geisteswelt, Auflösung der Seele im Nirvana, dem großen Nichts [...].

Nicht das Interesse für die Geschichte oder Religion Tibets führte also zum Zusammenhalt, sondern eine Projektion. Wie die Tibeter*innen durch die Ansiedlung von Chines ${ }^{\star}$ innen zur Minderheit mit bedrohter Kultur im eigenen Land wurden, ${ }^{142}$ so die Rätoroman ${ }^{*}$ innen durch die Zuwanderung anderer Sprachgruppen. Und wie die Tibeter*innen - »quei valerus pievel muntagnard « (»jenes tapfere Bergvolk«), ${ }^{143}$

140 Vgl. z. B. Erwähnungen des Zen-Buddhismus in: La Quotidiana, 5. November 1998, 23. Oktober 2002 .

141 Vgl. Dumengia saira, 1903, Nr. 7, S. 49-51, hier S. 49 f.

142 Vgl. z. B. La Quotidiana, 12. Januar 2005.

143 Vgl. La Casa Paterna, 1959, Nr. 39. 
"glieud sempla, diligenta ed engraziaivla « (»einfache Leute, fleißig und dankbar «), ${ }^{144}$ die »ân sco nus bugent la libertad« (»wie wir die Freiheit schätzen«) -, so lebten auch die Rätoroman^innen, gemäß Selbstbild, in wunderschönen Gebirgslandschaften. Tibet sei »in paradis dellas selvischinas, ella ei la patria dils lufs ed uors, mo era de tscharvas, capricorns, asens - e cavals selvadis« (»ein Paradies für Wildtiere, sie ist die Heimat der Wölfe und Bären, aber auch der Hirsche, Steinböcke, Esel - und wilden Pferde «), meinte etwa die Casa Paterna. ${ }^{145}$ Auf den Zusammenhang zwischen der rätoromanischen Positionierung für Tibet und ihrer eigenen Situation als Sprachminderheit, der sich wohl auf die insgesamt negative Rezeption Chinas ab 1950 ausgewirkt hat, verweisen auch allgemeine Berichte zur Politik Chinas, zumal diese, vor allem im 21. Jahrhundert, auffallend oft die Lage der Minderheiten thematisieren. ${ }^{146}$

Satirische Texte im Chardun (Die Distel, 1971-1991; 2004-2015) und der Quotidiana nahmen dann die sprachpolitische Situation der rätoromanischen Minderheit als Anlass für eine Annäherung des Rätoromanischen an das Chinesische. Für die deutsche Bevölkerung der Schweiz seien beide Sprachen, eine davon Landessprache, unbekannt und fremd, beide müssten erst noch in Sprachkursen erlernt werden, meinte Il Chardun 1976. ${ }^{147}$ Torlach Mac Con Mí, ein irischer Autor, der gleichzeitig englische und gälische Beiträge für die Dubliner Irish Times und das Raidió na Gaeltachta wie auch rätoromanische für La Quotidiana verfasst, kam in seinem Text »Ina soluziun >made in China per ils problems grischuns« (»Eine Lösung > made in China ‘ für die Bündner Probleme«), ausgehend von den Erfahrungen mit der Digitalisierung des Wörterbuches Dicziunari Rumantsch Grischun (DRG), auf eine Idee, um die Fremdheit und gleichzeitig die hohen Kosten, die der Erhalt des Rätoromanischen in Graubünden verschlingt, zu überwinden. 2017-2018 wurden alle damals vorhandenen Bände des $D R G$ in einem Transkriptionszentrum in Nanjing abgetippt, wobei die Frauen, zehntausende Seiten kopierend, weder ein Wort kannten noch vor Beginn ihrer Arbeit von der Existenz der Sprache in Kenntnis standen. ${ }^{148}$ Die gesamte rätoromanische Kultur nun, so die Idee, könnte nach China ausgelagert (outgesourct) werden, was Geld sparen würde. Außerdem wären die Rätoroman*innen in Graubünden dann wieder freigestellt, wie alle anderen Deutsch zu sprechen. Indessen könnte die chinesische Bevölkerung der Bergregi-

144 Vgl. La Casa Paterna, 1963, Nr. 21.

145 La Casa Paterna, 1950, Nr. 44, vgl. auch ebd., 1950, Nr. 34; Gasetta Romontscha, 10. April 1959, 8. März 1963; Calender Per mintga gi, 1965, S. 111-116.

146 Vgl. z. B. L’Aviöl, September 1998, März 2017; La Quotidiana, 11. Juli 2003, 25. September 2004, 29. September 2011, 25. Juli 2012, 28. April 2015, 10. August 2016, 22. August 2018.

147 Vgl. Il Chardun 6 (1977), Nr. 7, S. 25.

148 Vgl. La Quotidiana, 11. Dezember 2018; Bertilla Giossi: Made in China. La digitalisaziun dal Dicziunari Rumantsch Grischun, 07.12.2018, https://m.rtr.ch/play/tv/cuntrasts/video/ made-in-china---mit-deutschen-untertiteln?id=9f6fade9-dcb5-4404-92ef-5b7eb8d752ad (Zugriff 09.08.2020). 
on Gung-Ho ${ }^{149}$ in einem Lager in der Wüste Gobi zu Rätoroman*innen umerzogen werden. Der Kumpane Xi und die Mitglieder des Politbüros jedenfalls seien bereit für eine Kooperation. ${ }^{150}$

\section{Weder Daoismus noch Go oder Xiangqi}

Während die politischen Nachrichten aus China in rätoromanischen Zeitungen ab 1950 zunehmend verschwanden, mehrten sich ab 2005 Berichte von Rätoroma*innen, die China bereisten oder dortselbst arbeiteten und studierten, reziprok solche über Chines*innen, die rätoromanische Regionen besuchten, etwa Chinas bekanntester Rockmusiker Cui Jian 崔健 $\left({ }^{\star} 1961\right)$ die Surselva. ${ }^{151}$ Wir wollen an dieser Stelle die Reiseberichte - zu nennen wären vor allem jene von Lisa Dermont, die 2012 und 2015 aus Beijing schrieb ${ }^{152}$ - nicht weiter vorstellen.

Bevor wir zu China in der rätoromanischen Literatur kommen, sei jedoch noch kurz umrissen, inwiefern die chinesische Kultur, besonders deren Künste und Philosophien, in rätoromanischen Periodika ein Thema waren. Das Interesse für die chinesische Medizin, das im 21. Jahrhundert zur Eröffnung chinesischer Arztpraxen in rätoromanischen Regionen sowie zum Besuch von Shaolin-Mönchen und anderen Kampfkünstlern in Ftan und Tschlin führte, ${ }^{153}$ ist durch zwei Artikel der Dumengia Saira im Engadin bereits 1908 und 1915 zu bemerken. Beide Artikel erklären, durchaus ohne Spott, »sco cha il meidi chinais conclüda dad indizis externs sülla malatia da seis patiaints« (»wie der chinesische Arzt aus externen Anzeichen auf die Krankheit seiner Patienten schließt «). ${ }^{154}$ Vorgestellt werden Anzeichen der Augen, der Zunge, des Atems, der Nägel und auch der Perzeption, worauf dann erklärt wird, auf welche gegenwärtige oder zukünftige Krankheit diese Anzeichen hinweisen könnten. Zur Methode heißt es dann:

149 Eine fiktive, »überenthusiastische« Region.

150 Vgl. La Quotidiana, 9. Januar 2019, S. 12. Für eine weitere Satire mit Verwendung von China siehe Il Chardun, 2. November 1987.

151 Vgl. Fußnote 2 sowie La Quotidiana, 6. März und 26. Oktober 1998, 23. April 2001, 17. Februar und 8. Juni 2006, 12. Oktober 2010, 4. Juni 2014, 29. September 2015, 11. und 20. Juni sowie 3 . August 2017, 28. Februar und 4. Oktober 2018, 20. Januar und 25. Februar 2020. Vgl. auch Fögl Ladin, 31. Mai 1996.

152 Vgl. La Quotidiana, 6. und 15. Juni, 3., 6., 12., 17. und 24. Juli, 30. Oktober sowie 26. November 2012, 30. Juli und 3. September 2015.

153 Vgl. Fögl Ladin, 31. Mai 1996, La Quotidiana, 9. August 2010, 4. Juni 2015, 26. Februar und 7. November 2016, 13. Dezember 2018, 19. Februar 2019; Susanna Fanzun: Shaolin a Tschlin - Corsin Biert e l'art da cumbatter, 16.12.2018, www.rtr.ch/play/tv/cuntrasts/video/shaolin-atschlin---corsin-biert-e-lart-da-cumbatter---mit-deutschen-untertiteln?id=f34300c1-4c084fed-bd99-e4179dd70aaf (Zugriff 25.08.2020), vgl. auch Chalender ladin, 2007, S. 146-151.

154 Dumengia saira, 1915, S. 195; vgl. auch ebd., 1908, S. 71 f. 
Ad ün chi ha las viroulas nairas, e chi ais in consequenza da que in privel da gnir orb, cussaglian els: »Uondscha teis frunt cun terra alba, offera a teis idol ün bes-ch e dà a mai 50 frs! «155

Einem, der die echten Pocken hat, und deswegen in Gefahr steht, blind zu werden, empfehlen sie: »Schmiere deine Stirn mit weißer Erde ein, opfere deinem Götzen ein Schaf und gib mir 50 CHF!«

Häufiger als der Buddhismus (siehe Ziffer 8) wird in rätoromanischen Periodika der Konfuzianismus erwähnt. Moralische Sprüche, die Konfuzius zugeordnet werden, sind ab den 1880er Jahren etwa zehn Mal zu finden. ${ }^{156}$ Längere Ausführungen zum Konfuzianismus verweisen bevorzugt auf einzuhaltende Hierarchien zwischen Herrschern und Untergeordneten, Älteren und Jüngeren oder Eltern und Kindern. ${ }^{157}$ Eine Benimmregel aus einer anonymen Sammlung in der Dumengia Sai$r a$ von 1907 lautet: „Scha ün giarsun va con seis maister sün via, schi non il dess el bandunar e neir discuorrer cun oters, ch'el inscuntra. El non dess neir ir a pêr da seis maister, dimperse el dess ir ün pa davo el.« (»Wenn ein Lehrling mit seinem Meister auf der Straße geht, dann soll er ihn nicht verlassen und auch nicht mit anderen sprechen, die er trifft. Er soll auch nicht neben seinem Meister gehen, sondern ein wenig hinter ihm. «) ${ }^{158}$ Das Bild des Konfuzius scheint demnach das eines Moralisten gewesen zu sein, der für jede denkbare Handlung eine Benimmregel aus dem Sack zaubert, oder aber, wie dann in der »Erziehungsdiktatur « des Chiang Kai-shek 1934, ein Verbot: »Wascht euch! Seid höflich! Betrinkt euch nicht! Spuckt nicht! Uriniert nicht in der Öffentlichkeit! Haltet die Stadt sauber! « ${ }^{159}$ Der andere Konfuzius, der zum Teil in seiner Skepsis an den Sokrates des frühen Platon erinnert, war abwesend. In den Gesprächen (Lun yu 論語) heißt es zu diesem Konfuzius: »Er wusste viel, lernte aber auch bei denen, die weniger wussten. Er war sich stets seiner Grenzen bewusst. Voll von Wissen, hielt er sich dennoch für leer«, und variiert: »Konfuzius sprach: >Weiß ich viel? Nein, durchaus nicht.« oder: »Von vier Dingen war der Meister völlig frei: Er war frei von Voreingenommenheit, von Absolutheit, die keinen Zweifel zuläßt« ${ }^{160}$ Zudem scheint der Philosoph auch gerne Wein getrunken zu haben, und dies nicht zu wenig. ${ }^{161} \mathrm{Da}$ man aber eher am dogmatischen

155 Dumengia saira, 1915, S. 198.

156 Vgl. Fögld'Engiadina, 16. September 1882; Il Chardun, 2. November 1975; Calender Romontsch, 1998; La Quotidiana, 12. Juni 2014; Dun da Nadal (Uniun romontscha Renania), 1980, S. 41; Dumengia Saira, 1907, Nr. 2, S. 16.

157 Vgl. Dumengia saira, 1907, Nr. 2, S. 16; Gazetta Ladina, 1923, Nr. 51; Gasetta Romontscha, 31. Juli 1930.

158 Dumengia saira, 1907, Nr. 6, S. 48.

159 Vogelsang: Geschichte Chinas, S. 520.

160 Konfuzius: Gespräche / Lun yu, übers. von Ralf Moritz, Stuttgart: Reclam, 2017, S. 47 (VIII, 5), 52 (IX, 8) und $51(\mathrm{IX}, 4)$.

161 Vgl. Konfuzius: Gespräche / Lun yu, S. 54 (IX, 16) und 60 (X, 8). 
Konfuzius festhielt, erwischte der Konfuzianismus in der rätoromanischen Presse, beispielsweise anlässlich des Vortrags eines gewissen P. Walser 1901 in Pontresina, die entsprechende Bewertung: »Per mez da sia doctrina e da sieu exaimpel illatschet el ils Chinais in ün formalismo, chi suprima tuotta individualited e staundschainta nel nascher ogni libra emoziun del cour." (»Mittels seiner Doktrin und seines Beispiels schnürte er die Chinesen in einen Formalismus, der alle Individualität überwindet und das freie Mitteilen aller Herzensregungen erstickt. «1 ${ }^{162}$

Diese Deutung ist nicht weiter überraschend, mehr hingegen die Nichtbeachtung des Daoismus in rätoromanischen Periodika. Das Daodejing 道德經, in deutschsprachiger Kultur geradezu ein Bestseller, kommt kein einziges Mal vor, und Laozi 老子 (6. Jh. v. Chr.) wird 1938 nur einmal zusammen mit Konfuzius und Buddha Shakyamuni aufgezählt, ${ }^{163}$ dann erscheint er erst wieder 1971 in Igl noss sulom (1922-1991) mit einem Spruch. ${ }^{164}$ Zhuangzi wurde gar nicht erst erwähnt, zumindest nicht explizit. Versteckt ist er zum Teil Urheber jener Sprüche, die Konfuzius zugeschrieben wurden. Der Dun da Nadal der Uniun Romontscha Renana von 1980 enthält zum Beispiel einen `Spruch des Konfuzius‘, der jedoch im ersten Abschnitt des siebzehnten Buchs des humorvollen Zhuangzi zu finden ist: »Ti sas buca plidar cun ina rauna da fontauna sur digl ocean." (»Du kannst nicht mit einem Brunnenfrosch über den Ozean sprechen.« ${ }^{165}$ Und der Spruch des Konfuzius mit dem ersten Schritt und den tausend Meilen im Chardun ${ }^{166}$ stammt eigentlich aus dem Daodejing, Kapitel 64. Deswegen mag zusammengefasst sein: Der Buddhismus wurde in der rätoromanischen Presse als eine Philosophie à la Mainländer mit dem Ziel des Nichts als absolutes Nicht-Sein gedeutet, der Konfuzianismus als ein dogmatischer Formalismus, der Daoismus gar nicht. Wie sah das im Falle der chinesischen Künste aus?

Kommen chinesische Maler*innen und Illustrator*innen vor? Keine. Wurden chinesische Bilder abgedruckt? Nur einmal, in der Schülerzeitschrift Tschuetta (Eule, 1995-2007) von 1995, und zwar fünf Bilder zur Papierherstellung aus dem Tian gong kai wu 天工開物 von $1637 .{ }^{167}$ Spielt die chinesische Filmkultur eine Rolle? Zwei chinesische Filme, die im Kino in Tusáun (Thusis) liefen, wurden kurz zu-

162 Vgl. Fögl d'Engiadina, 20. April 1901.

163 Vgl. Gazetta Ladina, 1938, Nr. 52 supplemaint.

164 Vgl. Igl noss sulom, 1971, S. 144.

165 Dun da Nadal (Uniun Romontscha Renania), 1980, S. 40; vgl. Zhuangzi: Das Buch der Spontaneität. Über den Nutzen der Nutzlosigkeit und die Kultur der Langsamkeit. Das klassische Buch daoistischer Weisheit, übers. von Victor H. Mair und Stephan Schuhmacher, Aitrang: Windpferd, 2008, S. 193. Für den Hinweis auf Zhuangzi bedanke ich mich herzlich bei Marc Winter.

166 Vgl. Chardun, 2. November 1975, S. 24.

167 Vgl. Tschuetta, 1995, S. 59 f. Für den Hinweis zum Tian gong kai wu herzlichen Dank an Marc Winter. 
sammengefasst. ${ }^{168}$ Chinesische Musik ist nicht zu hören, doch beklagt sich die $\mathrm{Ga}$ setta Romontscha 1956 über ein Gastspiel der Oper und des Balletts aus Beijing in Zürich, da sie kommunistische Propaganda befürchtete. ${ }^{169}$ Woanders werden noch kurz die Erfindung der Mundorgeln in China sowie ein im Westen komponierter Chinesen-Marsch notiert. ${ }^{170}$ Die chinesische Kulinarik bleibt, mit Ausnahme der armen Pekingenten sowie der Feststellung, dass Konfuzius alle Gerichte mit Ingwer gewürzt hätte, beiseite. ${ }^{171}$ Von Spielen wird nur das Tangram erwähnt. ${ }^{172}$ Weder finden wir das chinesische Schach Xiangqi noch das geniale Weiqi (Go) noch MahJongg. Schauen wir nun, wie es mit der chinesischen Literatur und China in rätoromanischer Literatur aussieht.

\section{Vom chinesischen Kaiser zum wandernden Tee}

In Scuol wurde in den 1820er Jahren über die Einführung oder Nicht-Einführung einer Volksschule gestritten. Dazu gab es verschiedene Vorträge, unter anderem den eines Bauers namens J. Marchi: »Representanza fatta d'un baur. Als seis convaschins da Schuls, per l'Instituziun d'üna Schola comüna. Stampa a Strada. A[nno] 1827« (»Präsentation eines Bauern. An seine Mitbürger von Scuol, für die Institution einer Volksschule. Gedruckt in Strada. Im Jahr 1827 «). »Non sporscharai l'oraglia à quels chi vegnen as dir: per ün Baur, ò ün chi va davent non voula tantas Scholas" (»Hört nicht auf diejenigen, die euch sagen werden: Für einen Bauern, oder einen der weggeht, braucht es nicht so viele Schulen«), sprach Marchi zu den Versammelten. Entgegen diesen Argumenten wies der Vortragende besonders auf drei Punkte hin. Erstens würden viele Engadiner Bauern auch ehrenvolle Posten in den Ämtern des Kantons und der Schweizerischen Eidgenossenschaft einnehmen, wozu eine Schulbildung von Vorteil sei. Zweitens wäre eine Schule auch für junge Auswander*innen von Nutzen, wie am Beispiel der Oberengadiner*innen zu sehen sei, die in allen Ländern größten Erfolg hätten und in höchstem Maße respektiert und geehrt würden. Schließlich sei auch die Landwirtschaft selbst Grundlage der Ausbildung und des Wissens und »In Ægipto, in Græcia, pro ils Romans eiren ils plü famus Generals, \& dictat urs [sic] della Religiun, cultivaturs della terra " (»in Ägypten, Griechenland und bei den Römern seien die bekanntesten Generäle und Religionsführer zugleich Landwirte gewesen «). Nach dieser Stelle erscheint dann leicht überraschend der chinesische Kaiser, mit dessen Nennung J. Marchi die Scuoler zum Bau einer Volksschule zu überreden hoffte. Der chinesische Kaiser - gemeint war damit

168 Vgl. La Casa Paterna, 1994, Nr. 8; 1995, Nr. 41. X̌̀yàn von Ang Lee 李安 und Chóngqing Sēnlin von Wong Kar-Wai 王家衛.

169 Vgl. Gasetta Romontscha, 19. September 1956.

170 Vgl. La Quotidiana, 7. August 2009, 23. Juli 2020.

171 Vgl. Calender Per mintga gi, 1983, S. 135; La Quotidiana, 17. Juli 2012, 7. März 2018.

172 Vgl. L’Aviöl, Februar 1990. 
ein anonymer Kaiser oder aber der jiaqing- 嘉慶 oder daoguang-Kaiser 道光 - genoss im Unterengadin einen guten Ruf:

Amo preschaintamaing il plü potent, \& rich in pövel \& intradas, il Jmperadur della China, cun tuots seis Ministers honura svess da propria maun l'art della Cultivatiun della Terra ogni Ann, \& in tuot seis Jmpêri non puo ün sperár d' obtegner caricas grandas, sch' ün non ais instrui bain nel art della cultivatiun della terra, il prüm. ${ }^{173}$

Noch heute würdigt der mächtigste, \& in der Anzahl seiner Untergebenen \& Einkünften reichste Mann der Welt, der Herrscher Chinas, mitsamt seinen Ministern, jedes Jahr eigenhändig die Kunst der Landwirtschaft, \& in seinem Reich kann keiner hoffen, große Ämter zu erhalten, wenn er nicht zunächst in der Landwirtschaft gut ausgebildet ist.

China wurde in den Volksschulen des Unterengadins weiter thematisiert, denn einige Jahre später, 1863, ließ der Lehrer Flurin Valentin von Sent im Gedicht Il Tè da China ed il Tè d'Europa aus seinem Buch Poesias compostas per l'ütil dellas Scolas (Gedichte verfasst zum Nutzen der Schule) wiederum ein chinesisches Subjekt auftreten, diesmal - nicht unähnlich den handelnden Gurken in Grandvilles Un autre monde von $1844^{174}$ - in Form des personifizierten chinesischen Tees. Die ersten beiden Strophen lauten:

\section{Il Tè da China ed il Tè d'Europa}

Il tè gnônd del impêr chinais

Incuntret la buna (Malvia)

Questt'il schêt: cumpar ingió iais?

In Europa cumar Salvia.

Ingió ch'i in cumpran ad ôt prétsch.

Ed êu chamin invers la China,

Ingió da mia sôrt non és,

Là im cognóschens la glout fina. ${ }^{175}$

173 Vgl. J. Marchi: Representanza fatta d'un baur. Als seis convaschins da Schuls, per l'Instituziun d’üna Schola comüna. Stampa a Strada. $A^{\circ}$. 1827, in: Rätoromanische Chrestomathie, hg. von Caspar Decurtins, Bd. 8, Erlangen: Fr. Junge, 1907 (Romanische Forschungen, Bd. 24), S. 75-84, hier S. 77.

174 Vgl. Grandville: Un autre monde. Transformations, visions, incarnations, ascensions, locomotions, explorations, pérégrinations, excursions, stations, cosmogonies, fantasmagories, rêveries, folatreries, facéties, lubies, métamorphoses, zoomorphoses, lithomorphoses, métempsycoses, apothéoses, et autre choses, Paris: H. Fournier, 1844, S. 63.

175 Vgl. Flurin Valentin: Poesias compostas per l'ütil dellas Scolas, Cuoira: Senti \& Humme, 1863, S. 32. In der zweiten Gedichtzeile wird in Klammern die Malve erwähnt, gemeint war damit wohl, wie in der vierten Zeile genannt, Salbei - oder umgekehrt. 


\section{Der Tee aus China und der Tee aus Europa}

Der aus dem chinesischen Reich ankommende Tee

Traf den guten Salbei.

Dieser sagt ihm: Wohin gehst du, Freund?

Nach Europa, Freund Salbei.

Wo man mich für einen hohen Preis kauft.

Und ich laufe nach China,

Wo es meinesgleichen nicht gibt,

Dort kennen mich die feinen Leute.

Salbeitee war anscheinend im China des 19. Jahrhunderts beliebt, in Europa dagegen chinesischer Tee - offenbar auch im Engadin. Zwar befindet sich in der Chesa Planta in Samedan ein grober chinesischer Tisch des 19. Jahrhunderts, aber solche Gegenstände wurden von reicheren Familien gekauft und waren nicht sehr verbreitet. Chinesischer Tee und China-Rosen hingegen, worauf Werbungen aus dem Fögl d'Engiadina verweisen, waren gefragt. Dazu kamen anfangs des 20. Jahrhunderts noch chinesische Matten und Tinte. ${ }^{176}$ Aus den rätoromanischen Gebieten erreichten früher wohl wenige Güter China. 1912 etwa wurde versucht, Arsen-Mineralwasser aus der Val Sinestra nach China zu exportieren, was nicht geklappt hat. ${ }^{177}$

\section{Von Bluffern zu Li Bai}

Erfolgreicher war die Entwicklung des Dorfes San Murezzan hin zu einem internationalen Ort des Kurtourismus. Mitverantwortlich dafür war Conradin de Flugi (17871874), der sich für die Neufassung und Verwendung des Mineralwassers beziehungsweise »Heilwassers« einsetzte. ${ }^{178}$ Er besaß zugleich den Drang, etwas »al reviver e conserver del romaunsch« (»zum Beleben und Erhalten des Rätoromanischen«) beizutragen. ${ }^{179}$ Ein bekannter Tourismus- und Arbeitsort im Engadin könnte, so dachte

176 Vgl. Fögl d'Engiadina, 10. und 31. März 1866, 2. Juni 1900, 20. Dezember 1918, 25. November 1921, 7. November 1924; vgl. auch ebd., 22. November 1918, 23. August 1921.

177 Vgl. Korrespondenz von Gustav Pinösch-Gredig im Archiv Culturel d'Engiadin'Ota (Nachlass Pinösch-Gredig, Vulpera, Pontresina, Depot 5, 67d, Schachtel 18). Für Hinweise zum Nachlass herzlichen Dank an Dora Lardelli und Diana Pedretti.

178 Vgl. Johann Martin von Planta: Conradin von Flugi 1787-1874 und Alfons von Flugi 18231890, in: Bedeutende Bündner aus fünf Jahrhunderten, Chur: Calven, 1970, Bd. 1, S. 473-485, hier S. 477-479.

179 Vgl. Conradin de Flugi: Alchünas rimas romaunschas, Coira: Pargätzi \& Felix, 1861, S. 3 (Observaziun); Reto Raduolf Bezzola: Litteratura dals rumauntschs e ladins, Cuira: Lia Rumauntscha, 1979, S. 331. 
er, die Auswanderung der Rätoroman*innen abschwächen. ${ }^{180}$ Allerdings wurde aus San Murezzan recht bald St. Moritz, und fast niemand verstand mehr Flugis Sprache. 1861 erschien sein Gedichtband Alchünas rimas romaunschas und darin, im Gedicht Las quintèr sü ab der dritten Strophe, die Geschichte eines phantasievollen Bluffers:

Eau tuot las parts del muond chesista

He percurieu, tuot perscrutand,

Ma mè ais gnieu a mia vista

Un fat, sco uossa vegn quintand:

Na versa vis he nella China

Chi vaiva tel' enormited,

Cha suot si' ombra giav' adüna

A spass, il pövel d'la cited. ${ }^{181}$

Ich habe alle Teile der Welt, die existieren, durchrannt und dabei erforscht.

Aber noch nie ist mir vor Augen gekommen, ein Fall, wie ich ihn jetzt erzählen werde:

Einen Kohl habe ich in China gesehen, der hatte eine so unglaubliche Größe, dass unter seinem Schatten jederzeit die Bevölkerung der Stadt spazieren ging.

Wie Conradin de Flugi übertrug auch Gian Fadri Caderas (1830-1891) die im Engadin geschätzten humorvollen Übertreibungen in Poesie und fand dafür großartige Bilder. Im Gedicht Ün quinta sflötras (Ein Prahler) aus dem Band Sorrirs e larmas (Lachen und Tränen) von 1887 fällt zum Beispiel so viel Schnee im Engadin, dass die Hühner statt Körner die Sterne erreichen und picken können. ${ }^{182}$ In seinem Gedicht Tuot passa! (Alles verschwindet!) aus den Rimas von 1865 kam der Dichter zur philosophischen, beinahe buddhistischen Schlussfolgerung:

Fragil' ais la vita,

Sco del aragnun

Fragil' ais la taila;

Tuot ais illusiun! ${ }^{183}$

180 Vgl. Valeria Badilatti: Warten bis die Alten aus dem Dorf sind, in: Magazin piz 40 (2010), S. 40-42.

181 Vgl. Flugi: Alchünas rimas romaunschas, S. 17.

182 Gian Fadri Caderas: Sorrirs e larmas, Samedan: Simon Tanner, 1887, S. 56.

183 Vgl. Gian Fadri Caderas: Rimas, Coira: Braun \& Jenny, 1865, S. 10. 
Zerbrechlich ist das Leben,

Wie der Spinne

Zerbrechlich ist das Netz;

Alles ist Illusion!

Caderas, der sich wie de Flugi im liberalen und enthusiastischen Netzwerk der Engadiner Hotelpioniere bewegte, veröffentlichte 1887 in Sorrirs e larmas die ersten chinesischen Gedichte auf Rätoromanisch überhaupt: zwei Gedichte eines gewissen Tan Jo Su und ein Gedicht von Li Bai 李白 (701-762) aus der Tang-Dynastie. Da Caderas von 1880 bis zu seinem Tod als Hauptredaktor des Fögl d'Engiadina arbeitete $^{184}$ und in diesem Zusammenhang nicht nur zahlreiche Artikel zu den politischen Ereignissen in China verfasste - unter anderem vermutlich die Anklagen gegen den Imperialismus Frankreichs in Tonkin (siehe Ziffer 4) - sondern auch Berichte in anderen Zeitungen las, war ihm China nichts Fremdes. Auf die chinesischen Gedichte kam er durch Tullo Massaranis 1882 veröffentlichte italienische Übersetzung von Judith Gautiers Le livre de jade (1862). ${ }^{185}$ Das Gedicht von Li Bai, das 1887 in Samedan auf Rätoromanisch erschien, ist das Jing ye $s i$ 靜夜思. ${ }^{186}$

Im selben Jahr veröffentlichte der junge Dichter Peider Lansel (1863-1943) in den Annalas da la Societad Retorumantscha ein Gedicht namens Malà (Krank), das wie folgt beginnt:

Ün raz d'sulai aint in mia chombra croda

Bé sper meis let,

Debel sulai d'inviern chi nun rischoda.

Eu sun sulet! ${ }^{187}$

Ein Sonnenstrahl fällt in mein Zimmer

Gleich neben mein Bett,

Schwache Wintersonne, die nicht erwärmt.

Ich bin einsam!

Sowohl das Leuchten vor oder neben einem Bett als erste Szenerie des Gedichte, wie auch die Beschreibung von Kälte sowie von Einsamkeit (dieser Zustand wird im Gedicht von Li Bai traditionell hineingedeutet) mögen darauf hinweisen, dass Lansel Caderas' Version des Jing ye si bereits 1887 gekannt hat. Er war später im Besitz des li-

184 Vgl. Maxfield: Studies in Modern Romansh Poetry in the Engadine, S. 67.

185 Zur chinesischen Lyrik bei Caderas vgl. Rico Valärs Beitrag »Rätoromanische Nachdichtungen chinesischer Lyrik bei Gian Fadri Caderas und Peider Lansel. Eine Spurensuche« in diesem Band, S. 39-54.

186 Zum Jing ye si vgl. den Beitrag "Gedanken über Li Bais Jing ye si (Gedanken in einer stillen Nacht) und dessen Vertonungen im Westen" des Autors in diesem Band, S. 349-370.

187 Vgl. Annalas da la Societad Retorumantscha, 1887, S. 346. 
terarischen Nachlasses von Caderas, ${ }^{188}$ veröffentlichte 1930 eine eigene Edition zu Caderas' Lyrik ${ }^{189}$ und dichtete schließlich selber zwei chinesische Gedichte aus Gautiers Le livre de jade nach, Sül flüm Tschu (Aufdem Fluss Tschu) von Du Fu 杜甫 (712-770) und La flötna misteriusa (Die geheimnisvolle Flöte) von Li Bai. Sie erschienen erstmals 1911 im Fögl d'Engiadina, leicht variiert dann 1929 in seinem Buch Il vegl chalamêr (Das alte Tintenfass). ${ }^{190}$ Zwei weitere Nachdichtungen chinesischer Gedichte erschienen postum 1966, ${ }^{191}$ eine Version des Jing ye si und eine von Li Bais Gedicht Yue xia $d u$ zhuo 月下獨酌, wo sich der Poet zusammen mit seinem Schatten und dem Mond betrinkt.

\section{Vom Trinken und dem doppelten Po}

Li Bai, den Lansel vorerst gemäß Gautier als Li-Tai-Pe kannte, nach der Lektüre von Hans Bethges Die chinesische Flöte als Li Tai Po, ${ }^{192}$ führte ihn zu seinem Freund und Dichterkollegen aus Sent, zu Chasper Po. 1936 erschien nämlich in den Annalas ein Gedicht namens Filosofia veidra e plü co veidra (Alte und mehr als alte Philosophie), und in diesem Gedicht treten, neben einer Allusion an Caderas' »illusiun« aus den Rimas, ${ }^{193}$ beide Pos auf:

Filosofia veidra e plü co veidra

A l'ami Chasper Po

Teis dschench chinais, il sabi Li-tai-po

(vivü var dudeschtschient ans inavo)

disch, cha l'uman sün terr'ha povra sort, da sgür per el nu daja co la mort. Amur, richezza, glorgia, quai chi piglia tanta part in sa vita - be illusiun!

Lett'es da's tgnair vi da l'inspiraziun chattad'josom d'üna buna buttiglia. ${ }^{194}$

188 Dieser Nachlass befindet sich heute im Archiv der Chesa Planta in Samedan.

189 Vgl. Gian Fadri Caderas: Poesias. Ediziun in memorgia ed onur da sieu tschientanêr 1830-1930, hg. von Peider Lansel, Samedan: Engadin Press, 1930.

190 Vgl. Fögld'Engiadina, 28. Januar 1911; Peider Lansel: Il vegl chalamêr. Ediziun definitiva, Zürich: Gebrüder Fretz, 1929, S. 153.

191 Vgl. Peider Lansel: Poesias originalas e versiuns poeticas, hg. von Andri Peer, Samedan: Uniun dals Grischs e da la Lia Rumantscha, 1966 (Ouvras da Peider Lansel, Bd. 1), S. 225 f.

192 Vgl. auch Maxfield: Studies in Modern Romansh Poetry in the Engadine, S. 194.

193 Vgl. Caderas: Rimas, S. 10.

194 Vgl. Annalas da la Societad Retorumantscha 50 (1936), S. 180; vgl. auch Lansel: Poesias originalas e versiuns poeticas, S. 151. 


\section{Alte und mehr als alte Philosophie \\ Dem Freund Chasper Po}

Dein chinesischer Namensvetter, der weise Li-tai-po

(er lebte vor etwa zwölfhundert Jahren)

sagt, dem Menschen sei auf Erden ein armseliges Los beschieden, sicher sei ihm nur der Tod. -

Liebe, Reichtum, Ruhm, das, was im Leben

so viel Raum einnimmt - alles Illusion!

Besser tut man daran, sich an die Inspiration zu halten

auf dem Grund einer guten Flasche. ${ }^{195}$

Nur selten könne man die Engadiner Dichter vernehmen, aber wenn sie Wein trinken würden, dann »sun els in poesias / Diligaints sco las furmias « (»sind sie im Poesieren / Fleißig wie die Ameisen«) meinte M. Felix 1886 in seinem Gedicht Ils poets d'Engiadina ed il vin du Valtelina (Die Engadiner Dichter und der Veltlinerwein). ${ }^{196}$ Trinkgedichte ${ }^{197}$ reizten zu Nachahmungen, und ein Gedicht aus dem Jahre 1971 von Emigl Buchli (1908-1975) aus Lavin scheint implizit auf Lansels Trinkgedicht Filosofia veidra e plü co veidra zu referieren, das heißt auf den doppelten Po, auf Li und Chasper Po:

Il vin

(Discussiun intuorn maisa)

»O spiert dal vin, tü est il diavel in persuna!«

Quai disch ün grand scriptur inglais,

E la sentenza dal Chinais

Es different' e tuna:

»La cuolpa schi's vain aiver

Nun es il vin, ma'l baiver.«

Che disch Jon Tschütsch dal vin?

El svöd' il prüm seis bun quintin:

195 Die Übersetzung stammt von Dumenic Andry, vgl. auch dessen Beitrag »Chasper Pos Humor in diesem Band, S. 15-38.

196 Vgl. Annalas da la Societad Retorumantscha 1 (1886), S. 356. Zum Verhältnis von Wein und Dichten im Engadin vgl. auch Domenic Planta: La marella. Poesias, Schlarigna: Uniun dals Grischs, 1952, S. 68.

197 Vgl. z. B. auch Thomas Gross: Referat supra il poet populer Gian Battista Sandri, in: Annalas da la Societad Retorumantscha 17 (1903), S. 1-13 und ebd., S. 59. 
»Quai ch'oters dischan nu'm va pro.

Eu sun neutral, lap, quai ch'eu po. «198

Der Wein

(Gespräch um den Tisch)

»O Geist des Weins,

Du bist der Teufel in Person!«

Dies sagt ein großer englischer Schriftsteller,

Und das Urteil des Chinesen

Ist unterschiedlich und klingt:

"Schuld am Betrunken-Werden

Ist nicht der Wein, sondern das Trinken.«

Was sagt Jon Sauger zum Wein?

Zuerst leert er sein gutes Gläschen:

»Was andere sagen, geht mich nichts an.

Ich bin neutral, sauf, was ich kann. «199

Li Bai kommt als alkoholliebender Chinese vor, Chasper Po wäre Jon Tschütsch. Zuerst weil dieser ganz anarchisch für sich denkt, dann weil das Gedicht mit "po« endet, was auf Chasper Pos Gedicht Cumgià (Abschied) und dessen viele Varianten verweist: »Gugent vess fat ailch >comme il faut / ma nö’adüna Chasper po« (»Gerne hätte ich etwas >comme il faut ‘ gemacht / aber nicht immer kann [= po] Chasper «). ${ }^{200}$

\section{Lyrische Nachrichten zum Boxerkrieg}

Chasper Po (1856-1936) selbst verfasste ebenfalls vier Gedichtstrophen zu China, in denen statt des Weins der Boxerkrieg behandelt wird. Sie sind als Bestandteil eines lyrischen Jahresberichts in den Annalas von $1901 \mathrm{zu}$ finden:

198 Vgl. Emigl Buchli: Svutrada, Chur: Bischofberger \& Co, 1971, S. 28.

199 Die deutsche Fassung bei Buchli lautet: »Der Geist im Wein / kann nur der Teufel sein! / Ein Weiser Brite spricht dies Wort, // Und der Chinese fährt dann fort: / »Enthaltsamkeit - ein lahmes Spiel. / Wer kotzen muss, der hat zuviel.« // Und unser Hans, / (er ist schon heiter): / »Der Wein ist gut, / ich trinke weiter.« Buchli, Svutrada, S. 29.

200 Vgl. Chasper Po: Rimas, hg. von Göri Klainguti und Clà Riatsch, Schlarigna: Uniun dals Grischs, 1996, S. 56. Wie Chasper Po übertrug zudem auch Emigl Buchli Texte von Wilhelm Busch. Vgl. Chalender Ladin, 1975, S. 65 f. 
"Cunter la forza la radschun non vaglia«

Dischan riand quels, chi as saintan ferms:

E amo rimprovers fan alla "canaglia",

Ch' els zappan, sco chi füssan misers verms,

"L' ais«, dischan, »ün armaint sten malprüvà;

Perfin as dost' el, cur ch' el vain tizzià!«

E lur rapinas cun bels pleds cuvernan,

Ot declamand da civilisaziun.

Ma che? - cler 's vezza eir sainza linterna,

Cha que ais tuot be simulaziun:

Laschai ognün patrun in seis pajais,

Laschai la gelga China als gelgs Chinais.

Scha quel colur ad els ais plü simpatic

E scha ad els plü plaschan stivals ots,

Scha prefereschan il mangiar asiatic

Ed oters üsits, oters chants e sots,

Laschai chi fetschan! seis gust ha minchün,

Sco disch eir il proverbi dal giattin.

Del rest, güst els pon dir, cha sco cultura

Eiran a nus, e forsa eir sun, avant;

Bain veglia e richa ais lur litteratura

E puolvra e stampa là plü d' ün infant

Già cognoschaiva, cur noss antenats

A chi faiva seis nom dschaivan scienziats. ${ }^{201}$

"Gegen Macht gilt das Recht nicht«

Sagen lachend jene, die sich stark fühlen:

Und machen dem »Gesindel« noch Vorwürfe,

Dass sie umherzappeln, als wären sie dämliche Würmer,

»Es ist«, sagen sie, »ein recht unerzogenes Viehstück;

Es wehrt sich sogar, wenn es geneckt wird!»

Und ihre Raubzüge verdecken sie mit schönen Worten, Hoch die Zivilisation deklamierend.

Aber was? - Klar sieht man auch ohne Laterne,

Dass all das nur Heuchelei ist: 
Lasst jeden selber Herr in seinem Land sein,

Lasst das gelbe China den gelben Chinesen.

Wenn diese Farbe ihnen mehr zusagt

Und wenn ihnen hohe Stiefel besser gefallen,

Wenn sie das asiatische Essen vorziehen

Und andere Bräuche, andere Gesänge und Tänze,

Lasst es sie tun! Jeder hat seinen Geschmack,

Wie dies auch das Sprichwort der Katze ${ }^{202}$ sagt.

Nebenbei, gerade sie können sagen, dass sie als Kultur

Uns voraus waren, und vielleicht immer noch sind;

Alt und reich ist ihre Literatur,

Und Schießpulver und Buchdruck kannte dort

Schon jedes Kind, als unsere Vorfahren noch

Jeden, der sich irgendwie hervortat, einen Wissenschaftler nannten.

Die zitierten Gedichtstrophen sind eine Anklage gegen die Unterdrückung der Chinesen durch den europäischen Imperialismus sowie gegen den Feldzug der Alliierten unter Alfred von Waldersee (der in einer anderen Strophe als »barunet $"=$ Barönchen, schlechter Kerl, Schurke ${ }^{203}$ bezeichnet sein mag) nach Beijing, die stärker nicht formuliert sein könnte. »Laschai la gelga China als gelgs Chinais« wird mittels Kursivschrift geradezu herausgeschrien, und in der ersten der oben erwähnten Strophen zeigt sich auch Pos Entrüstung über den Zynismus. Die vierte Strophe entspricht den aus Zeitungen und Zeitschriften bekannten Rekordlisten ${ }^{204}$ und die dritte bildet Chasper Pos anti-dogmatische politische Haltung ab. Bemerkenswert ist zudem Pos Erwähnung der reichen chinesischen Literatur in der letzten Strophe: Anscheinend kannte auch er Li Bai und andere chinesische Autor ${ }^{\star}$ innen.

Giovannes Mathis (1824-1912) aus Schlarigna kam auf den Boxerkrieg wegen eines Streits zwischen den Gemeinden Samedan und Bever zu sprechen. Gestritten, allerdings mit der Schreibfeder, wurde damals über den zukünftigen Ort des Haupt-

202 »A minchün seis gust, dschaiva il giat, as lichand il chül« (»Jedem sein Geschmack, sagte die Katze, sich den Hintern leckend «), in: Andrea Vital: Proverbis, in: Annalas da la Societad Retorumantscha 13 (1899), S. 141-162, hier S. 141. Für den Hinweis herzlichen Dank an Dumenic Andry.

203 Vgl. Zaccaria Pallioppi/Emil Pallioppi: Dizionari dels idioms romauntschs d'Engiadinota e bassa, della Val Müstair, da Bravuogn e Filisur con particulera consideraziun del idiom d'Engiadin'ota, Samedan: Stamparia da Simon Tanner, 1895, S. 96.

204 Das Älteste, Größte, die ersten Erfindungen usw. In Periodika meistens erwähnt werden die chinesische Mauer, das Papier, das Papiergeld, die Zeitung, der Buchdruck, der Kompass, das Porzellan und die Verwendung von Stahl, das Schießpulver und das Automobil. Vgl. z. B. Fögl d'Engiadina, 5. September 1919; Gazetta Ladina, 3. Juni 1938; Calender Romontsch, 1962, S. 70-72; La Tschuetta, 1995, S. 59-60; La Quotidiana, 21. März 2007; La Casa Paterna, 1940, Nr. 46; L’Aviöl, 1979; ebd., Dezember 1997. 
bahnhofs. Die letzte Strophe seines 1901 im Fögl d'Engiadina publizierten Gedichts klingt wie folgt:

O, füssan d'China e Transvaal, Sco dals degns fils da nossa val, Be guerras d'pennas e sorrir, E dal muond pêsch sieu avvegnir. ${ }^{205}$

O, gäbe es in China und Transvaal, Wie bei den würdigen Söhnen unseres Tals, Nur Kriege von Schreibfedern und Lachen, Und Frieden wäre die Zukunft der Welt.

Mathis' Strophe versucht in erster Linie die Streitereien im Engadin durch Verweise auf wirkliche Kriege zu relativieren. Zwar fehlt wie bei Chasper Po die Anklage, trotzdem scheint implizit auch Mathis den Boxerkrieg abzulehnen, da er sich insgesamt eine Ersetzung der Waffen mit Schreibfedern sowie eine Welt des Friedens wünscht.

Im Inhalt ganz anders als Chasper Pos lyrischer Kommentar zum Boxerkrieg, geradezu entgegengesetzt - verwandt aber im bitteren Klang - ist ein Gedicht namens China von Alfons Tuor aus Rabius:

\section{China}

Gl' uffiern oz triumfesch' en part asiata, Sfraccont la Crusch tras paganiglia schliata.

Chinès mazzacran cun torments sgarscheivels, Eunc strusch s' udi, tuts ils christifideivels.

Mo franc gl' uffiern selegra adumbatten, Che lacs de seun christian pertut tschalattan: Il seun de marters fa il tratsch fritgeivels, Ch' el porta bia pli biars christifideivels. ${ }^{206}$

\section{China}

Die Hölle triumphiert heute im asiatischen Teil, indem das Kreuz durch boshaftes Heidenvolk zerstört wird.

206 Annalas da la Societad Retorumantscha 15 (1901), S. 147; vgl. auch Alfons Tuor: Poesias, hg. von Renzo Caduff, Cuera: Chasa Editura Rumantscha, 2015, S. 287. 
Chinesen massakrieren mit schrecklichen, noch kaum dagewesenen Foltern alle Christen.

Aber gewiss, die Hölle freut sich vergeblich, dass überall Fluten von christlichem Blut wogen:

Das Märtyrerblut macht die Erde fruchtbar, damit sie umso mehr Christen gebärt.

Alfons Tuor (1871-1904), der an einer Knochentuberkulose und Hüftschmerzen litt, dachte streng katholisch und pilgerte zwischen 1897 und 1899 drei Mal nach Lourdes, da er auf ein Wunder hoffte. Er unterrichtete zwischen 1899 und 1900 im Kloster Disentis Rätoromanisch und arbeitete dort an der Edition seines Gedichtbandes Magnificat II. ${ }^{207}$ Tuor bezeichnet die Chines*innen als Heid*innen und Mörder*innen, die Aggression der Imperialmächte aber bleibt ungenannt, da sie direkt mit dem Missionswesen verbunden war. Das Gedicht von Tuor entspricht gewissermaßen einer lyrischen Variante der Boxerkriegberichte in der Gasetta Romontscha, so wie das von Chasper Po jenen des Fögl d'Engiadina (siehe Ziffer 5). Erstaunlicherweise wurden die Boxerkrieg-Gedichte von Po und Tuor in derselben Ausgabe der Annalas publiziert. Nun aber, das ist klar, verteidigten nicht alle im Engadin wie Chasper Po die Boxer*innen ${ }^{208}$, genausowenig wie alle Bewohner*innen der katholischen Surselva mit dem China-Bild der GR oder des Alfons Tuor in dessen Komödien öfters Pseudochinesisch erklingt - übereinstimmten. In seiner Übertragung von Molières Le médecin malgré lui (Il Doctor per forza) etwa erfindet der geschwätzige Holzfäller Sganarelle (Lezi) nicht nur Latein, Hebräisch und Griechisch, sondern dazu Chinesisch, nämlich »tschintschang «. ${ }^{209}$ Giachen Mihel Nay (1860-1920), um ein Gegenbeispiel aus der Surselva zu nennen, kritisiert in seiner Erzählung Il Giuncher de Crap marsch (Der Junker von Faulenstein) das Vorgehen der Europäer in China, »che han en lur nas e grugn en mintga puglina (»die ihre Nase und Schnauze in jeden Vogeldreck stecken«) und Reichtümer stehlen. »Saperlot, quei dat de patertgar« (»Verflixt, das gibt zu denken«). ${ }^{210}$

\section{Atombomben, Sprüche und Erzählungen}

Ab der zweiten Hälfte des 20. Jahrhunderts verringerte sich die Anzahl politischer Nachrichten aus China in den rätoromanischen Zeitungen, die mehr und mehr re-

207 Vgl. Renzo Caduff: Alfons Tuor. Portret biografic, in: Alfons Tuor: Poesias, hg. von Renzo Caduff, Cuera: Chasa Editura Rumantscha, 2015, S. 9-39, hier S. 29, 32, 34, 35.

208 Vgl. z. B. Robert Ganzoni in: Annalas da la Societad Retorumantscha 17 (1903), S. 315.

209 Vgl. Tuor: Il Doctor per forza, S. 77, vgl. auch ders.: Il Gierau de Schlans, S. 9.

210 Vgl. Giachen Mihel Nay: Il Giuncher de Crap marsch, in: Annalas da la Societad Retorumantscha 16 (1902), S. 220-243, hier S. 222 f. Für die Hinweise zu Nay und Tuor herzlichen Dank an Renzo Caduff. 
gionalen Charakter bekamen (siehe Ziffer 8). Hie und da wurde die Mitbeteiligung Chinas am Vietnamkrieg der 1960er Jahre erwähnt, oder Chinas Bau der Atombombe 1964. Die Gasetta Romontscha wies zudem auf eine »bumba atomara spirtala" (geistige Atombombe) hin, nämlich Mao Zedongs »cudischet tgietschen " (rotes Büchlein), das Mao zhuxi yulu 毛主席語錄, und bezeichnete den Verstorbenen im selben Nachruf als »ina persuna singulara, ton politicher sco poet (»außergewöhnliche Person, sowohl als Politiker wie Dichter «). ${ }^{211}$ Beide, Mao wie die Atombombe, erscheinen dann in zwei Gedichten aus Gion Tscharners tissi ambrosian (Ambrosianisches Gift) von 1966. Mao kommt im Gedicht Tgi es tei (Wer bist du) vor, die Atombombe in Mund (Welt). Von Weltuntergangs-Stimmung und Desorientiertheit sind beide Gedichte geprägt, letzteres mag an Kriegsszenen aus Vietnam erinnern:

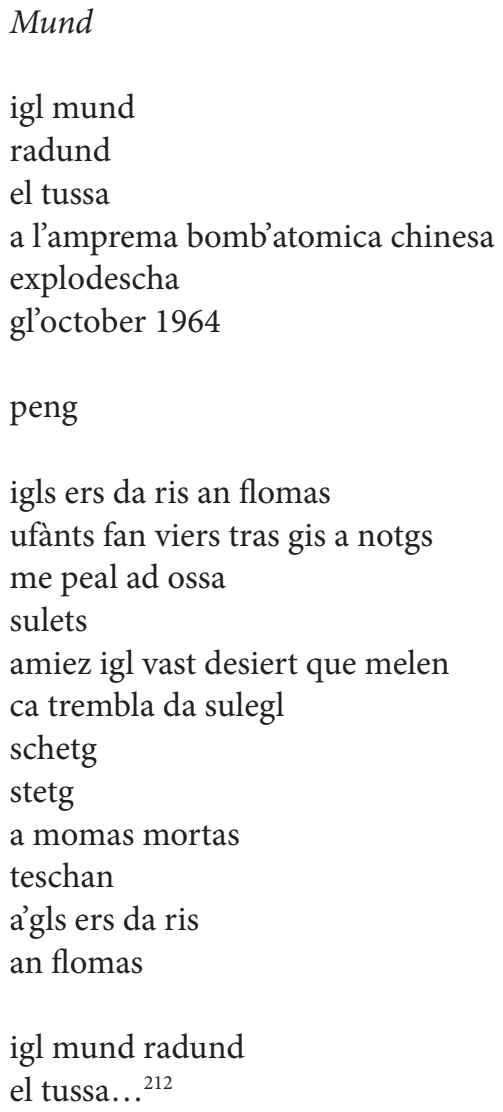




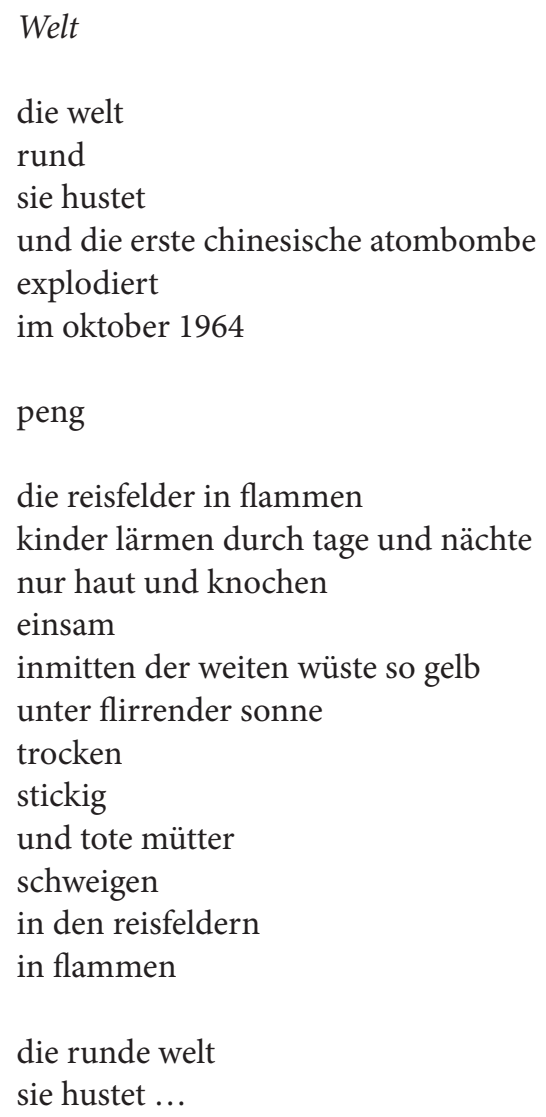

Eine Stimmung der Desorientiertheit herrscht auch in Dumeni Capeders (19342017) Roman La porta dalla libertad? von 1984. Erzählt wird im ersten Drittel die Flucht von chinesischen Vietnamesen auf einem Boot. In unserem Zusammenhang, dem Bild Chinas in rätoromanischer Literatur, ist aber besonders ein zitierter Spruch auf Seite 39 von Interesse: »La qualitad digl aur / emprov'ins el fiug; / quella dil carstgaun / ella sventira « (»Die Qualität des Goldes / lässt sich im Feuer prüfen; / die des Menschen / im Unglück«). ${ }^{213}$ Dieser Spruch stamme von Li-Tai-Po, wird angemerkt, doch fehlen Quellenangaben. Immerhin treffen wir aber den Dichter der Tang-Zeit, nach Caderas und Lansel, auch bei Capeder an.

Chinesische Sprüche, meistens irgendwelche sogenannten Weisheiten, sind in rätoromanischen Zeitschriften ab dem Ende des 19. Jahrhunderts zu finden. Gemäß diesem Brauch lässt auch Capeder jedes Kapitel seines Romans mit einem Spruch einleiten und veröffentlichte Not Vital 2017 ein ganzes Buch: 201 proverbis, tradüts da Not Vital in pled da Sent (201 Sprichwörter, übersetzt von Not Vital nach Sprechart von

213 Vgl. Dumeni Capeder: La porta dalla libertad?, Mustér: Desertina, 1984, S. 39. 
Sent). Er hätte diese chinesischen Sprichwörter seit einem Jahr in Beijing übersetzt, heißt es im Prolog. Welchen Büchern die Sprichwörter entnommen wurden, ist unklar, und viele Sprichwörter mögen deswegen reizend sein, weil sie zur gegenteiligen Behauptung reizen. Einzelne der übersetzten chinesischen Sprichwörter enthalten Engadiner Spuren, beispielsweise "plain in pigna«, sprich geraffelte Kartoffeln, die zusammen mit Maismehl und Knoblauch oder Salsiz im Ofen gebacken werden. ${ }^{214}$

Merkwürdiger als Sprüche sind die in rätoromanischen Periodika zitierten chinesischen Erzählungen, wovon es ungefähr zwei Dutzend gibt. Zwei Erzählungen wurden 1926 im Tramagliunz (Der Spielmann, 1926-1939) abgedruckt. In einer davon beerdigt ein Sohn seinen Vater. Am Beerdigungsort pflanzt er laut Wunsch des Verstorbenen Bäume und verkauft diesen Boden auch dann nicht, als Spekulanten, die darunter Steinkohle vermuten, ihn abkaufen wollen - dies sozusagen eine moralische Geschichte zum Ahnenkult gegen den Verkauf von Boden an Spekulanten, im Unterengadin etwa zugunsten des Tourismus. ${ }^{215}$ Acht chinesische Erzählungen präsentierte der Calender Per mintga gi 1970, zum Beispiel jene eines phantastischen Fasses, das alles multipliziert, leider am Schluss auch den toten Besitzer, weswegen dessen Sohn das multiplizierte Geld für die unendlich vielen Särge ausgeben muss. 1971 folgen sechs kleine, humorvolle Geschichten. Ein reicher Mann sagt zu einem Geizkragen: »Melli onzas dun jeu a ti, sche jeu astgel bastunar tei a mort « (»Tausend Unzen gebe ich dir, wenn ich dich totschlagen darf«). »Dai tschuntschien« (»Gib fünfhundert«), meint der andere, »e bastuna mei mo mezmorts (»und schlage mich nur halbtot «). ${ }^{216}$ Von unheimlicher Stimmung dann, ähnlich wie man sie mitunter im Liaozhai Zhiyi 聊齋志異 des Pu Songling 蒲松齡 (1640-1715) antrifft, ist eine »istorgia chinaisa « (»chinesische Geschichte«), die Oscar Peer in seiner Erzählung Il figl (Der Sohn) einflocht. Hauptfiguren sind wiederum Sohn und Vater. Der Erstgenannte befindet sich anscheinend nicht »sülla dretta via« (»auf dem rechten Weg«) und der Vater kann ihn nicht ändern, nur beobachten. Er sieht seinen Sohn wie in einem dichten Wald, durch das Gestrüpp, manchmal als Statur, dann wieder als Schatten. Eines Tages, alt geworden und mit schwachem Blick, betritt er diesen Wald und läuft zu einem Fluss, wo er sich lange als gebückten Mann betrachtet. Dann sieht er plötzlich, statt sich selbst, das Gesicht seines Sohnes, »chi til surria our da las uondas« (»das ihn aus den Wellen anlächelt«). ${ }^{217}$

Vermutlich nur einmal wurde im Zusammenhang mit rätoromanischer Literatur explizit ein Werk aus der chinesischen Literatur genannt, das Jinpingmei 金瓶梅 aus dem 16. Jahrhundert in Leo Tuors Essay »Suppe, Huhn und Zauberzahl«. Ausgangslage des Essays sind rätoromanische Beschreibungen von Speiseplänen und

214 Vgl. Not Vital: 201 proverbis tradüts da Not Vital in pled da Sent, Ardez: fundaziun Not Vital, 2017, S. 125, 167.

215 Il Tramagliunz 1 (1926), Nr. 5; 2 (1927) Nr. 6; weitere chinesische Geschichten in La Casa Paterna, 1961, Nr. 15 sowie L'Aviöl, November 2015, S. 25-27.

216 Vgl. Calender Per mintga gi, 1970, S. 18-20; 1971, S. 94 f.

217 Vgl. Oscar Peer: Il figl, in: ders.: Intermezzos, Schlarigna: Uniun dals Grischs, 2002 (Chasa Paterna, Bd. 121), S. 64 f. 
Esswaren, besonders ein Kochbuch namens »Cudisch de Cuschinar « aus der Surselva und die Hexameter-Kantate auf das Küchenwesen Il Gioder von Giacun Hasper Muoth. Dazu meint Leo Tuor satirisch, und wir verweisen auf eine ähnliche Argumentation in den chinesischen Satiren des Chardun (siehe Ziffer 8):

Zwar gibt es in der klassischen Literatur der Rätoromanen gargantueske Beispiele und ellenlange Register im Rhythmus der Schiffskataloge der »Ilias« darüber, welche Speisen der Reihe nach auf den Tisch kommen. Ein Bild, wie es da zu- und hergeht, kann dem des Rätoromanischen Unkundigen vielleicht der »jing Ping Mei« vage vermitteln. ${ }^{218}$

\section{Lotusblumen, Kamele und gelbe Flüsse}

Weder satirisch noch politisch, sondern schlicht als Teil eines Limericks wurden China und Taiwan 1996 bei Theo Candinas und 2012 bei Alfons Clalüna genannt. ${ }^{219}$ In beiden Gedichten geht es um Rätoromanen, die in China oder Taiwan arbeiteten und reisten; insofern bilden sie genau das ab, was ab den 1980er Jahren für die rätoromanischen Periodika zu bemerken ist (siehe Ziffer 9). In der rätoromanischen Literatur zeigt sich dies Ende der 1980er Jahre zuerst bei Peder Cadotsch (1922-2002). Er veröffentliche 1988 und 1989 in Igl noss sulom (Unsere Scholle, 1922-1991) die beiden Gedichte Flour da lotus (Die Lotusblume) und Igl mandarin (Der Mandarin) sowie 1992 in seinem Buch Anc sgolan las ronslas... (Noch fliegen die Schwalben ...) zwei zusätzliche Gedichte namens La gronda miraglia (Das große Gemäuer) und Igls suldos da Xi'an (Die Soldaten von Xi'an). ${ }^{220}$ Die beiden letztgenannten Gedichte entstanden vermutlich während oder nach einer Chinareise, auf der Cadotsch die chinesische Mauer sowie die Terrakotta-Armee des Kaisers Qin Shihuangdi 秦始皇帝 (259-210 v. Chr.) besuchte. In beiden vermischen sich Szenen der Gegenwart mit Vorstellungen der Vergangenheit; so verwandelt sich etwa der bei der Chinesischen Mauer vernommene Wind zum Seufzer eines verlassenen Herrschers, und aus den Spalten zwischen den Steinen scheinen Sklaven und Gefangene zu blicken, die ehemals als Zwangsarbeiter das Werk errichteten. ${ }^{221}$

218 Leo Tuor: Suppe, Hahn und Zauberzahl, in: ders.: Auf der Suche nach dem verlorenen Schnee, Zürich: Limmat, 2016, S. 209-217, hier S. 209.

219 Vgl. Theo Candinas: Limericks da Gion da Farglix, Surrein: Ediziun digl autur, 1996, S. 114; Alfons Clalüna: Engiadina narrais-cha, Schlarigna: Uniun dals Grischs, 2012, S. 34. Das Gedicht von Clalüna ist nicht im strengen Sinn ein Limerick, erinnert aber durch die Ortsangabe in der ersten Zeile (A d'eir'a Segl ün signur / Es war in Sils ein Herr) an eines.

220 Vgl. Igl noss sulom, 1988, S. 37; 1989, S. 54; Peder Cadotsch: Anc sgolan las ronslas..., Lucerna: Cadotsch-Gendre, 1992, S. 29-32.

221 Bei der Mehrheit der Bauarbeiter aber handelte es sich weder um Zwangsarbeiter noch um Gefangene, sondern um Soldaten. Vgl. Wenyuan Liu: Tales of the Great Wall, Beijing: Foreign Languages Press, 1997, S. 14. 


\section{La gronda miraglia}

Miraglias sa ruschnan

scu zerps crestadas

da val tar val

da colm tar colm,

scu etern rampar da protecziun.

Nò dalla steppa

bragia il vent

scu en suspeir

resignia

d'en imperatour banduno.

Or dallas fessas

tgittan îgls veids

da sclavs e parschuniers - -

ed ena schischeglia sa zoppa

davos en program.

Ed ainten la sadela

da rusment

sfrigna

tranter figlia menla

igl codesch cotschen da Mao!- _222

\section{Das große Gemäuer}

Gemäuer kriechen

wie Schlangen mit Kämmen

von Tal zu Tal

von Hügel zu Hügel

wie ein ewiger Verteidigungswall.

Von der Steppe her

schreit der Wind

wie ein resignierter

Seufzer

eines verlassenen Herrschers.

222 Cadotsch: Anc sgolan las ronslas..., S. 32. "zerps crestadas« (2. Zeile) kann auch Drachen bedeuten. 


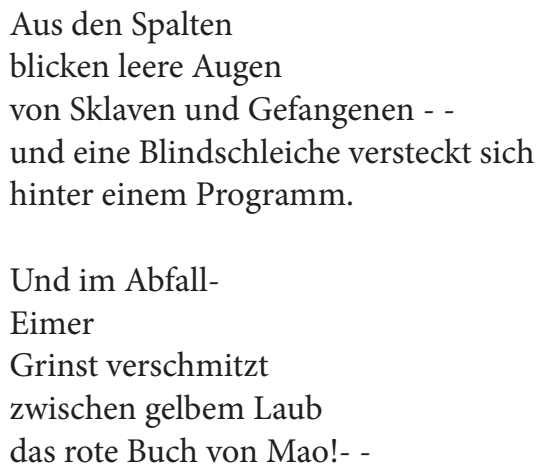

Ausschließlich in der Vergangenheit scheint sich Cadotschs Mandarin aufzuhalten:

\title{
Igl mandarin
}

\author{
Ainten la pagoda \\ digl sies iert \\ sesa \\ igl mandarin.
}

L'iglida inerta

reposa

ainten igl tgalesch

digl lotus avert.

Ena libella

sgola lomign

tras igl fons

silenzi!-

Angal igl mandarin

renescha

ainten l'armoneia

e la clerezza

dalla pasch celesta!-223 


\section{Der Mandarin}

In der Pagode

seines Gartens

sitzt

der Mandarin.

Der träge Blick

ruht

im Kelch

des geöffneten Lotus.

Eine Libelle

fliegt sanft

durch die tiefe

Stille!-

Doch der Mandarin

lebt auf

in der Harmonie

und Klarheit

des himmlischen Friedens!-

Der Mandarin mit seiner Umgebung - Pagoden, Gärten, Libellen, Lotusblumen (in Cadotschs Gedicht Flour da lotus schwimmt eine Lotusblume im Li Jiang wie eine Illusion ${ }^{224}$ und verschwinden Träume, zwischen Blüten, mit den Wellen) - ist eine außergewöhnliche Erscheinung in der rätoromanischen Literatur. Denn erstens ist es das einzige gefundene Beispiel einer Chinoiserie - also eines »dem Alltag entrückten Reichs «, in dem »eine dauernde `müßige Feiertagsstimmung` zu herrschen scheint $«^{225}$ - beziehungsweise eines Porzellan-Chinas, zweitens ist die Chinoiserie mit den 1980er Jahren recht spät angesetzt, sie erscheint gewissermaßen um 200 Jahre verspätet, und drittens ist der Duft von Lotus- und Jasminblüten in rätoromanischer Literatur eine Seltenheit, wo dort in der Regel ganz andere Düfte vorherrschen: »Bram sglisch'oura sün 'na buatscha, / Vzand las stailas vi'n Gravatscha" (»Bram rutscht aus auf einer buatscha [Kuhfladen] / und sieht die Sterne in Gravatscha $)^{226}$ Allerdings lassen sich immerhin chinesische Mandarine, als Bäume auftretend, auch in Andri Peers Gedichtband Insainas von 1984 finden. Im Gedicht Lecziuns utuonalas (Herbstliche Lektionen) zum Beispiel korrigiert der »tigl manda-

224 Vgl. Igl noss sulom, 1988, S. 37.

225 Vgl. Ingrid Schuster: Vorbilder und Zerrbilder. China und Japan im Spiegel der deutschen Literatur 1773-1890, Bern: Peter Lang, 1988, S. 283; Li: China als Muse, S. 42.

226 Comics Rumantschs, 1976, Nr. 1, S. 8. Gravatscha befindet sich zwischen Samedan und Bever. 
rin, / mellen da madüranza« (»die Mandarin-Linde, / gelb vor Reife«) lächelnd und großzügig die Gedichte der Seggen. ${ }^{227}$

Wie Peder Cadotsch hat später Leta Semadeni $\left({ }^{*} 1944\right)$ Erlebnisse in China, solche aus der Oasenstadt Dunhuang, aus Hotan und aus der Wüste Gobi in Monolog per Anastasia / Monolog für Anastasia von 2001 sowie aus der Wüste Taklamakan in In mia vita da vuolp / In meinem Leben als Fuchs von 2010 in Dichtung gefasst. In L'uffant mort da Chotan (Das tote Kind von Chotan) verarbeitete sie einen Blutfleck und einen einzelnen Plastikschuh, den sie in Xinjiang neben einer Autostraße bemerkte: "L'uffant mort sta sü / ans fa segn / e disch: / Tuot quai ch'eu nu poss tocker / am resta stran « (»Das tote Kind steht auf / und winkt uns zu / Es sagt: / Was ich nicht berühren kann / bleibt mir für immer fremd «). ${ }^{228}$ Ihre Wüstengedichte versuchen bestimmte Phänomene der Natur und die durch diese erzeugten Stimmungen einzufangen - das Silbergras, die Helle des Mondes, die Sanddünen, die Weite und die klaren Sterne oder in Dunghuang ein Kamel, auf die Schur wartend.

\section{Dunghuang}

Là

aint il desert

es la muntogna da coquiglias

culurida dals immens tschêls

Il chameil metta seis stizis in rudè

El doza il cheu e püffa per quai aint

Sainza discuorrer culla glüna

chi ha tantas fatschas

èll là ch'el spetta da gnir tus

pasculond las stailas

sponsas tanter las dünas

\section{Dunghuang}

Dort

in der Wüste

227 Vgl. Andri Peer: Insainas, in: ders.: Poesias 1946-1985, hg. von Clà Riatsch, Cuoira: Desertina, 2003, S. 385-415, hier S. 394; siehe auch S. 390. Für den Hinweis herzlichen Dank an Dumenic Andry.

228 Vgl. La Quotidiana, 22. Januar 2001; Leta Semadeni: Monolog per Anastasia Poesias / Monolog für Anastasia. Gedichte, Zürich: Nimrod, 2001, S. 59. Es handelt sich hier um die dritte Strophe des vierstrophigen Gedichts. 
steht das Muschelgebirge

von den grossen Himmeln gefärbt

Das Kamel umkreist den Muschelberg

Es hebt den Kopf und schaut dahin

Unberührt von der Fremdheit

des vielgesichtigen Mondes

wartet's

auf seine Schur

die Sternbilder grasend

die ausgestreut zwischen den Dünen

liegen $^{229}$

Naturphänomene Chinas oder chinesische Namen erscheinen auch in der Literatur von Rut Plouda ( $\left.{ }^{\star} 1948\right)$. In der ersten kurzen Erzählung aus Verd s-chür von 2020 sitzt ein Ich vor dem Laptop und sucht Ideen für einen Kurs. Es sieht durch das Fenster eine Schultafel, auf der ein Lehrer zwei Flüsse aufschreibt: »Jangtsekiang, il flüm blau e Hwangho, il flüm jelg« (»Jangtsekiang, der blaue Fluss, und Hwangho, der gelbe Fluss«). Beim Nachsprechen und Nachschreiben dieser Worte beginnt das Subjekt zu träumen, von Flüssen und ihren Namen, die sich vermischen - so wie in einzelnen Gedichten von Clementina Gilli oder Peider Lansel ${ }^{230}$ - vom Hwangho und der Clemgia, »e bod sun ils flüms pleds e bod suna auas chi culan...« (»und bald sind die Flüsse Wörter und bald sind sie Gewässer, die fließen ...«). ${ }^{231}$

\section{Abendessen in Shanghai und Einkauf in Beijing}

Häufiger als mit China verbundene Naturphänomene wurden in rätoromanischen Periodika Städte beschrieben, meistens Beijing und Hongkong. Besonders oft wurde Hongkong besucht, dessen Name wie »duos cuolps d’ün gong« (»zwei Schläge eines Gongs«) erschalle. ${ }^{232}$ Die Stadt erscheint in früheren Berichten vordergründig als unheimliche, dystopische Stadt, beinahe schlimmer als das spätere Los Angeles in Blade Runner (1982): völlig überbevölkert, ein Ort der Kluft zwischen Arm und Reich, der Flüchtlinge und Epidemien. ${ }^{233}$ Arno Camenisch $\left({ }^{*} 1978\right)$, er verfasste die

229 Ebd., S. $60 \mathrm{f}$.

230 Vgl. Clementina Gilly: Fruonzla, Coira: Bischofberger \& Hotzenköcherle, 1926, S. 6 f.; Lansel, Poesias originalas e versiuns poeticas, S. 28 und $86 \mathrm{f}$.

231 Vgl. Rut Plouda: Verd s-chür, Cuira: Chasa Editura Rumantscha, 2020, S. 7.

232 Vgl. Fögl Ladin, 6. September 1966.

233 Vgl. z. B. Gasetta Romontscha, 16. Oktober 1959; La Casa Paterna, 1961, Nr. 39; 1962, Nr. 22; Il giuven Grischun, November 1965, S. 13-15; Fögl Ladin, 3. März 1970, 1. März 1988. 
folgenden Beispiele auf Deutsch, erlebte in Hongkong eine verrückte Busfahrt mit einem halbblinden Fahrer, der unfähig war, eine Stadtkarte zu lesen, und dachte vielleicht an die Missionare der Surselva.

Der Bus schoss wie eine Rakete in der Dämmerung über die Strassen und ich dachte an den Bruader Claus mit dem schweren Motorrad, der mit der schönen Mei aus China durchbrannte und ins Verderben fuhr, während hinter den Scheiben Hongkong wie ein wilder Drache seine tausend Köpfe in den Himmel streckte. ${ }^{234}$

Am Abend folgte eine Einladung zum Abendessen in einer Hotelfachschule und die Bewirtung durch achtzehn Diener. An jeder Ecke, selbst in der Toilette, standen sie, darauf wartend, den Wasserhahn aufzudrehen und Handtücher zu servieren. »Erleichtert wie nach einem Verhör verliess ich die Toilette und atmete erst mal tief durch. Weiter vorne bei der Türe sah ich aber bereits den nächsten stehen, und wäre ich nicht rechtzeitig abgehauen, wäre der ganze Spass wohl weitergegangen bis zum Morgengrauen. $\ll^{235}$ Aus Beijing berichtete sodann Not Vital $\left({ }^{\star} 1948\right)$ in seinem Buch Kec' \& Frajas von 2019, wo auf Seite 8 auch das Gedicht 1 tschiervi (1 Hirsch) auf Chinesisch übersetzt wurde. Mit Ausnahme des Uorsin (1945) von Selina Chönz und Alois Carigiet wurden wohl keine weiteren Werke der rätoromanischen Literatur auf Chinesisch übersetzt. ${ }^{236}$ Not Vital ließ sich im Caochangdi 草場地 ein Haus bauen, wo er sich bevorzugt einschloss und bei schummrigem Licht Porträts malte. »A Beijing nu ris-chasch per dis a la lunga or dal studio, pervi cha dadora nu respirasch, l'ajer es uschè greiv. Sco hoz." (»In Beijing traust du dich tagelang nicht aus dem Studio, weil du draussen nicht atmen kannst, die Luft ist so schwer. Wie heute. « ${ }^{237} 2008$ verließ er trotzdem den Raum, und zwar, um in der IKEA irgendwelche Kissen einzukaufen. Aber: "Cun rivar pro'l departamaint da plümatschs veva güsta da laschar ir 1a« (»Bei der Kissen-Abteilung angekommen musste ich grad 1nen fahren lassen «). ${ }^{238}$ Und dies stank dermaßen, dass er sich gleich aus dem Staub

234 Arno Camenisch: In Hongkong, in: ders.: Die Launen des Tages, Schupfart: Engeler, 2016, S. 35-38, hier S. 38 .

235 Arno Camenisch: Zu Tisch in Hongkong, in: ders.: Nächster Halt Verlangen, Solothurn: Engeler, 2014, S. 39-41, hier S. 41.

236 Ins Japanische hingegen wohl. Nobuo Tomimori, der auch an der Tokyo University of Foreign Studies Rätoromanisch unterrichtete, gab 1980 eine Anthologie von Gedichten aus der Schweiz, darunter rätoromanische von Theo Candinas, Luisa Famos, Gian Fontana, Jon Guidon, Peider Lansel, Alexander Lozza, Andri Peer und Hendri Spescha auf Japanisch heraus: 富盛伸夫 (Nobuo Tomimori): Suisu shishū スイス詩集 (Sammlung Schweizerischer Gedichte), 東京: 早稲田大学出版部 (Tokyo : Waseda Daigaku Shuppanbu), 1980. Vgl. auch Fögl Ladin, 6. Januar 1989. Die Ausgabe des Uorsin in Chinesisch wäre: 賽琳娜 柯恩斯 (Selina Chönz): Ti zhe xiao ling dang de Wuli 提著小鈴鐺的鳥利 / übers. von Liu Mengying 劉孟穎, [Taibei]: Weibo wenhua guoji chuban youxian gongsi 韋伯文化國際出版有限公司, 2015.

237 Not Vital: Kec' \& Frajas. Poesias \& + oter, Ardez: Fundaziun Not Vital, 2019, S. 75.

238 Vgl. ebd., S. 95. 
machte und vermutlich in sein Studio zurückkehrte. Ganz gemäß dem Sprichwort: »Chi chi savura, lavura.« (»Wer duftet, arbeitet.«) ${ }^{239}$ Mit diesem Furz sei denn auch der deskriptive Teil dieses Essays abgeschlossen und gleichzeitig das Fazit eingeleitet.

\section{Schlussfolgerung}

Bis 1950 wurden in rätoromanischen Zeitungen erstaunlich viele politische Ereignisse in China geschildert - zum Teil, es sei an die Reportagen von A. Volkart-Christoffel erinnert, auch in hoher Qualität. Die politischen Nachrichten zu China verschwanden dann allmählich ab den 1950er Jahren, vierzig Jahre später mehrten sich aber Aufzeichnungen über Reise- oder Berufsaufenthalte in China. Im Verhältnis zur politischen Berichterstattung wurde die Kultur Chinas, etwa die Philosophie oder die Künste, in rätoromanischen Periodika eher selten thematisiert, wofür ich - ähnlich wie für das seltene Vorkommen von Li-Bai-Vertonungen in lateinischsprachigen Ländern - keine Gründe angeben kann. ${ }^{240}$ Doch scheint es zwischen der rätoromanischen Rezeption der Politik Chinas und der rätoromanischen Literatur mit chinesischen Elementen, die im Werk von mindestens dreiundzwanzig Autor*innen zu finden sind, Parallelen zu geben. Deutungen des Boxerkrieges zum Beispiel wurden 1901 bei Giovannes Mathis, Chasper Po und Alfons Tuor in Lyrik gefasst, 1902 bei Giachen Mihel Nay in Prosa. Und Reiseeindrücke in China spielten für viele Gedichte ab den 1980er Jahren eine Rolle, angefangen mit jenen von Peder Cadotsch, der zudem eine rätoromanische Chinoiserie erfand. Als erster scheint 1887 Gian Fadri Caderas chinesische Gedichte auf Rätoromanisch übertragen zu haben, solche von Tan Jo Su und Li Bai 李白. Daraufhin präsentierte Peider Lansel 1911 - ebenfalls auf Grundlage von Judith Gautiers Le livre de jade (1862) - Gedichte von $\mathrm{Li}$ Bai und $\mathrm{Du} \mathrm{Fu}$ 杜甫. Ansonsten aber scheint in der rätoromanischen nirgends die chinesische Literatur vorzukommen, mit Ausnahme der Nennung Li Bais bei Dumeni Capeder und des Jinpingmei 金瓶梅 bei Leo Tuor. Auch die Zeitungen haben dazu wenig zu berichten: zweimal wird Qu Yuan 屈原 (ca. 340-278 v. Chr.) im Zusammenhang mit den chinesischen Drachenbooten erwähnt, einmal Mao Zedong 毛澤東 als Poet. ${ }^{241}$ Trotzdem mag die chinesische Literatur nicht ganz unbekannt gewesen sein, denn Chasper Po bezeichnete sie 1901 als »bain veglia e richa" (»altehrwürdig und reich «). ${ }^{242}$ Eine weitere Erforschung des Chinabildes in rätoromanischer Kultur könnte Behauptungen und Darstellungen des vorliegenden Textes auf jeden Fall noch erweitern oder relativieren.

Vgl. ebd.

240 Vgl. den Beitrag »Quantitative Überlegungen zum Phänomen der Li-Bai-Vertonungen im Westen « des Autors in diesem Band, S. 219-239.

241 Vgl. Gasetta Romontscha, 14. September 1974; La Quotidiana, 3. Juli 2012, 6. Februar 2013.

Vgl. Annalas da la Societad Retorumantscha 15 (1901), S. 286. 


\section{Literatur}

Annalas da la Societad Retorumantscha, Cuira: Societad Retorumantscha, 1886-2020.

L'Aviöl. Gazettina pels scolars, Schlarigna: Uniun dals Grischs, 1916-2020.

L'Aurora d'Engiadina, Strada: Fl. Janett Schiarplatz, 1843-1844.

Badilatti, Valeria: Warten bis die Alten aus dem Dorf sind, in: Magazin piz 40 (2010), S. 40-42.

Bezzola, Reto Raduolf: Litteratura dals rumauntschs e ladins, Cuira: Lia Rumauntscha, 1979.

Billigmeier, Robert H.: Land und Volk der Rätoromanen. Eine Kultur- und Sprachgeschichte, Frauenfeld: Huber, 1983.

Buchli, Emigl: Svutrada, Chur: Bischofberger \& Co, 1971.

Caderas, Gian Fadri: Poesias. Ediziun in memorgia ed onur da sieu tschientanêr 1830-1930, hg. von Peider Lansel, Samedan: Engadin Press, 1930.

Caderas, Gian Fadri: Sorrirs e larmas, Samedan: Simon Tanner, 1887.

Caderas, Gian Fadri: Rimas, Coira: Braun \& Jenny, 1865.

Cadotsch, Peder: Anc sgolan las ronslas..., Lucerna: Cadotsch-Gendre, 1992.

Caduff, Renzo: Alfons Tuor. Portret biografic, in: Alfons Tuor: Poesias, hg. von Renzo Caduff, Cuera: Chasa Editura Rumantscha, 2015, S. 9-39.

Calender Per mintga gi: Calender popular per las valladas renanas, Cuera: Casanova, 1921-1981.

Calender Romontsch, Mustér: Condrau, 1860-2020.

Camenisch, Arno: In Hongkong, in: ders.: Die Launen des Tages, Schupfart: Engeler, 2016, S. 35-38.

Camenisch, Arno: Zu Tisch in Hongkong, in: ders.: Nächster Halt Verlangen, Solothurn: Engeler, 2014, S. 39-41.

Camenisch, Silvio: Metamorfosas. Las pintgas metamorfosas els temps dallas grondas murias, Mustér: Desertina, 1989.

Candinas, Theo: Limericks da Gion da Farglix, Surrein: Ediziun digl autur, 1996.

Candreia, Jakob: Die romanische und italienische Journalistik, Bern: Jent \& Co., 1896.

Cantieni, Anna Maria: Geschichte der rätoromanischen Presse in Graubünden, Vaz: A. M. Cantieni, 1984.

Capeder, Dumeni: La porta dalla libertad?, Mustér: Desertina, 1984.

Caratsch, Reto: Grischuns a l'ester. Glorias e misiergias da trais seculs d'emigraziun, in: ders.: Ouvras, Zernez: Ediziun dal Chardun, 1983, S. 183-217.

Casa Paterna / La Púnt. Organ dall'Uniun romontscha renana, Cuera: Bischofberger, 1920-1996.

Chalender grischun, Coira: Stamp. hert. Otto, 1855-1885.

Chalender ladin. Cudesch per la famiglia rumantscha, Schlarigna: Uniun dals Grischs, 1911-2020.

Chang, Iris: The Rape of Nanking. The Forgotten Holocaust of World War II, New York: BasicBooks, 1997.

Chardun. Revista rumantscha, Zuoz, 1971-1991, 2004-2015.

Chönz, Selina 賽琳娜 柯恩斯: Ti zhe xiao ling dang de Wuli 提著小鈴鐺的鳥利, übers. von Liu Mengying 劉孟穎, [Taibei]: Weibo wenhua guoji chuban youxian gongsi 韋伯文化國 際出版有限公司, 2015.

Clalüna, Alfons: Engiadina narrais-cha, Schlarigna: Uniun dals Grischs, 2012.

Collenberg, Adolf: Der Atem des Faschismus im Spiegel der romanischen Presse 1922-1937, in: Bündner Monatsblatt. Zeitschrift für bündnerische Geschichte und Landeskunde, Chur: Desertina, 1988, Nr. 6, S. 347-363. 
Comics rumantschs, Zuoz: ediziun rumantscha, 1975-1991.

Corv e Talina. Prüma Gasetta interromontscha, Mustér: La Talina, 1965-1975.

Dabringhaus, Sabine: Die Boxer. Motivation, Unterstützung und Mobilisierung, in: Kolonialkrieg in China. Die Niederschlagung der Boxerbewegung 1900-1901, hg. von Mechthild Leutner und Klaus Mühlhahn, Berlin: Christoph Links, 2007, S. 60-68.

Decurtins, Caspar (Hg.): Rätoromanische Chrestomathie, Bd. 2, bearbeitet von Peter Egloff und Jon Mathieu, Chur: Octopus Verlag, 1982.

Decurtins, Caspar (Hg.): Rätoromanische Chrestomathie, Bd. 15 (Register), bearbeitet von Peter Egloff und Jon Mathieu, Chur: Octopus Verlag, 1986.

Dumengia saira, Samedan: Engadin Press, 1894-1916.

Dun da Nadal alla giuventetgna romontscha, Cuera: Uniun Romontscha Renana, 1922-1993.

Dun da Nadal als infants ladins / Dun da Nadal. Il cudaschin divertent pel temp d'Advent, Schlarigna: Uniun dals Grischs, 2012-2020.

Engiadinais, Coira: Stamp. Fl. Gengel, 1876-1882.

Fanzun, Susanna: Shaolin a Tschlin - Corsin Biert e l'art da cumbatter, Scuol, 2018, www.rtr. ch/play/tv/cuntrasts/video/shaolin-a-tschlin---corsin-biert-e-lart-da-cumbatter---mitdeutschen-untertiteln?id=f34300c1-4c08-4fed-bd99-e4179dd70aaf (Zugriff 16.08.2020).

Flugi, Conradin de: Alchünas rimas romaunschas, Coira: Pargätzi \& Felix, 1861.

Fögl d'Engiadina. Organ del public, Zuoz, Samedan: 1858-1939.

Fögl Ladin. Giasetta independenta per l'Engiadina e contuorns, Samedan: Societed d'Ediziun Fögl Ladin, 1940-1996.

Gazetta Ladina, Scuol: Bischofberger \& Hotzenköcherle, 1922-1939.

Gilly, Clementina: Fruonzla, Coira: Bischofberger \& Hotzenköcherle, 1926.

Giossi, Bertilla: Made in China. La digitalisaziun dal Dicziunari Rumantsch Grischun, https://m.rtr.ch/play/tv/cuntrasts/video/made-in-china---mit-deutschen-untertiteln?i d=9f6fade9-dcb5-4404-92ef-5b7eb8d752ad (Zugriff 09.08.2020).

Giuven Grischun. Fegliet meinsil per la giuventetgna romontscha grischuna, Cuoira: Lia Rumantscha, 1965-1970.

Glogn. Calender per il pievel romontsch, Glion: Maggi, 1927-1953.

Grandville: Un autre monde. Transformations, visions, incarnations, ascensions, locomotions, explorations, pérégrinations, excursions, stations, cosmogonies, fantasmagories, rêveries, folatreries, facéties, lubies, métamorphoses, zoomorphoses, lithomorphoses, métempsycoses, apothéoses, et autre choses, Paris: H. Fournier, 1844.

Gross, Thomas: Referat supra il poet populer Gian Battista Sandri, in: Annalas da la Societad Retorumantscha 17 (1903), S. 1-13.

Hölzl, Marcus: Tibet. Vom Imperium zur chinesischen Kolonie, Frankfurt am Main: Peter Lang, 2009 (Politik und Demokratie, Bd. 16).

Hool, Catherine: Die chinesische Tibetpolitik unter besonderer Berücksichtigung der Jahre 1976-1988, Bern: Peter Lang, 1989 (Schweizer Asiatische Studien, Bd. 9).

Hsia, Adrian: China-Bilder in der europäischen Literatur, Würzburg: Königshausen \& Neumann, 2010 (Saarbrücker Beiträge zur vergleichenden Literatur- und Kulturwissenschaft, Bd. 49).

Kaiser, Dolf: Cumpatriots in terras estras. Prouva d'üna documentaziun davart l'emigraziun grischuna, considerand in speciel l'Engiadina e contuorns, Samedan: Stamparia engiadinaisa 1968. 
Klein, Thoralf: Aktion und Reaktion? Mission und chinesische Gesellschaft, in: Kolonialkrieg in China. Die Niederschlagung der Boxerbewegung 1900-1901, hg. von Mechthild Leutner und Klaus Mühlhahn, Berlin: Christoph Links, 2007, S. 32-42.

Klein, Thoralf: Die Basler Mission in Guangdong (Südchina) 1859-1931. Akkulturationsprozesse und kulturelle Grenzziehung zwischen Missionaren, chinesischen Christen und lokaler Gesellschaft, München: Iudicium, 2002.

Konfuzius: Gespräche / Lun yu, übers. von Ralf Moritz, Stuttgart: Reclam, 2017.

Kuzmin, Sergei L.: Der blutige weiße Baron und die Fakten, in: Berndt Krauthoff/Michael Haupt: Ich befehle! Kampf und Tragödie des Barons Ungern-Sternberg, hg. von Sergei L. Kuzmin, Kiel: Regin, 2011, S. 309-331.

Lansel, Peider: Poesias originalas e versiuns poeticas, hg. von Andri Peer, Samedan: Uniun dals Grischs e da la Lia Rumantscha, 1966 (Ouvras da Peider Lansel, Bd. 1).

Lansel, Peider: Il vegl chalamêr. Ediziun definitiva, Zürich: Gebrüder Fretz, 1929.

Lechner, Ernst: Die periodische Auswanderung der Engadiner und anderer Bündner, Samaden: Engadin Press Co., 1912.

Li, Daniela: China als Muse. Produktive Rezeption chinesischer Literatur und Kultur in der deutschen Literatur des 20. und 21. Jahrhunderts, Berlin: Christian A. Bachmann, 2015 (Studia Comaparatistica, Bd. 5).

Liu, Weijian: Kulturelle Exklusion und Identitätsentgrenzung. Zur Darstellung Chinas in der deutschen Literatur 1870-1930, Bern: Peter Lang, 2007 (Deutsch-Ostasiatische Studien zur interkulturellen Literaturwissenschaft, Bd. 7).

Liu, Wenyuan: Tales of the Great Wall, Beijing: Foreign Languages Press, 1997.

Mainländer, Philipp: Philosophie der Erlösung. Erster Band, hg. von Lennart Piro, Scotts Valley: CreateSpace, 2014.

Marbach, Otto: 50 Jahre Ostasienmission. Ihr Werden und Wachsen, Berlin/St. Gallen: Ostasienmission, 1934.

Marchi, J.: Representanza fatta d'un baur. Als seis convaschins da Schuls, per l'Instituziun d’üna Schola comüna. Stampa a Strada. A ${ }^{\circ}$. 1827, in: Rätoromanische Chrestomathie, hg. von Caspar Decurtins, Bd. 8, Erlangen: Fr. Junge, 1907 (Romanische Forschungen, Bd. 24), S. 75-84.

Maxfield, Mildred Elizabeth: Studies in Modern Romansh Poetry in the Engadine, with Special Consideration of Zaccaria Pallioppi (1820-1873), Gian Fadri Caderas (1830-1891) and Peider Lansel (1863-), Cambridge, MA: M. E. Maxfield, 1938.

Michael-Caflisch, Peter: Hier hört man keine Glocken. Geschichte der Schamser Auswanderung nach Amerika und Australien, Baden: hier + jetzt, 2008.

Mohr, Anton: Predgias evangelicas salvadas a Celin, Samaden: Stamparia Tanner, 1897.

Mühlhahn, Klaus: China und der westliche Imperialismus, in: Kolonialkrieg in China. Die Niederschlagung der Boxerbewegung 1900-1901, hg. von Mechthild Leutner und Klaus Mühlhahn, Berlin: Christoph Links, 2007, S. 15-26.

Nay, Giachen Mihel: Il Giuncher de Crap marsch, in: Annalas da la Societad Retorumantscha 16 (1902), S. 220-243.

Nobuo Tomimori 富盛伸夫 (Hg.): Suisu shishū スイス詩集 (Sammlung Schweizerischer Gedichte), 東京: 早稲田大学出版部 (Tokio: Waseda Daigaku Shuppanbu), 1980.

Noss sulom, Coira: Uniun Rumantscha da Surmeir, 1922-1991. 
Nowak, Dominik: Der Tod des deutschen Gesandten Clemens von Ketteler, in: Kolonialkrieg in China. Die Niederschlagung der Boxerbewegung 1900-1901, hg. von Mechthild Leutner und Klaus Mühlhahn, Berlin: Christoph Links, 2007, S. 111-117.

Ossendowski, Ferdinand: Tiere, Menschen \& Götter, Erkrath: Strange 2001.

Ostertag, Albert: Tschin, der arme Chinesenknabe und Vater Bodelschwingh, Basel: Basler Missionsbuchhandlung, 1911.

Ostertag, Albert: Tschin, il pover giuven chines, übers. von Anton Mohr, Basel: J.J. Mast, 1855.

Ott-Marti, Anna Elisabeth: Tibeter in der Schweiz. Kulturelle Verhaltensweisen im Wandel, Erlenbach ZH: Rentsch, 1971.

Pallioppi, Zaccaria/Pallioppi, Emil: Dizionari dels idioms romauntschs d'Engiadin'ota e bassa, della Val Müstair, da Bravuogn e Filisur con particulera consideraziun del idiom d'Engiadin'ota, Samedan: Stamparia da Simon Tanner, 1895.

Peer, Andri: Insainas, in: ders.: Poesias 1946-1985, hg. von Clà Riatsch, Cuoira: Desertina, 2003, S. 385-415.

Peer, Oscar: Il figl, in: ders.: Intermezzos, Schlarigna: Uniun dals Grischs, 2002 (Chasa Paterna, Bd. 121), S. $64 \mathrm{f}$.

Pelegrin. Amitg della casa christiana, Mustér: Condrau, 1900-1969.

Pfister, Gallus: Vier romanische Komponisten, in: Bedeutende Bündner aus fünf Jahrhunderten, Chur: Calven, 1970, Bd. 2, S. 391-414.

Planta, Domenic: La marella. Poesias, Schlarigna: Uniun dals Grischs, 1952.

Planta, Johann Martin von: Conradin von Flugi 1787-1874 und Alfons von Flugi 1823-1890, in: Bedeutende Bündner aus fünf Jahrhunderten, Chur: Calven, 1970, Bd. 1, S. 473-485.

Plouda, Rut: Verd s-chür, Cuira: Chasa Editura Rumantscha, 2020.

Po, Chasper: Rimas, hg. von Göri Klainguti und Clà Riatsch, Schlarigna: Uniun dals Grischs, 1996.

Pu Songling: Strange Tales from a Chinese Studio, übers. und hg. von John Minford, London: Penguin Books, 2006.

Quotidiana. Gasetta Romontscha, Cuira: Gasser Media, 1997-2020.

Rabe, John: The Good Man of Nanking. The Diaries of John Rabe, hg. von Erwin Wickert und übers. von John E. Woods, New York: Vintage Books, 2000.

RTR: La seguonda patria, Tibetans a Samedan / Die zweite Heimat. Tibeter in Samedan, in: Balcuntort,12.11.1978,www.rtr.ch/play/tv/il-balcun-tort/video/die-zweite-heimat-tibeterin-samedan?id=505669dc-fda4-4f6a-8237-024dcae6a307 (Zugriff 14.08.2020).

Schenk, Lukas: Tibet. Samedan: Eine Geschichte von Heimat und Flucht, 2008, https://vimeo. com/256758058 (Zugriff 09.08.2020).

Schreich, Rahel Seraina: Süllas passidas da l'emigraziun jaura dal 18avel tschientiner fin a la prüma guerra mundiala, Sta. Maria: R. S. Schreich, 2004-2005.

Schuster, Ingrid: Vorbilder und Zerrbilder. China und Japan im Spiegel der deutschen Literatur 1773-1890, Bern: Peter Lang, 1988.

Semadeni, Leta: In mia vita da vuolp. Poesias / In meinem Leben als Fuchs. Gedichte, Cuira: Chasa Editura Rumantscha, 2010.

Semadeni, Leta: Monolog per Anastasia. Poesias / Monolog für Anastasia. Gedichte, Zürich: Nimrod, 2001.

Sieberg, Herward: China im Zeitalter des Imperialismus, in: Der Boxerkrieg in China. Tagebuchaufzeichnungen des späteren Hildesheimer Polizeioffiziers Gustav Paul, hg. von Hubert 
Mainzer und Herward Sieberg, Hildesheim: Gebrüder Gerstenberg, 2001 (Quellen und Dokumentationen zur Stadtgeschichte Hildesheims, Bd. 11), S. 13-54.

Specker, Konrad: Aspekte der Beziehungen zwischen der Schweiz und China - eine historische Perspektive, in: Swiss-Chinese Chamber of Commerce Bulletin, Nr. 2, 2000, S. 30-57.

Spence, Jonathan D.: Chinas Weg in die Moderne, übers. von Gerda Kurz und Siglinde

Summerer, Bonn: Bundeszentrale für politische Bildung, 2008.

Sulom surmiran. Organ da l'Uniun Rumantscha da Surmeir, Savognin: Uniun Rumantscha Central, 1992-2007.

Tramagliunz. Supplemaint da la Gazetta Ladina, Scuol: Bischofberger \& Hotzenköcherle, 1926-1939.

Tscharner, Gion: tissi ambrosian, Tusàn: Roth, 1966.

Tschuetta, Donat: Uniun Romontscha Renana, 1995-2007.

Tuor, Alfons: Poesias, hg. von Renzo Caduff, Cuera: Chasa Editura Rumantscha, 2015.

Tuor, Alfons: Il Gierau de Schlans. Cumedia originala ord l'ujara franzosa en 1 act, Cuera: Stamparia de Jos. Casanova, 1897.

Tuor, Alfons: Il Doctor per forza (Le médecin malgré lui). Ina cumedia en 3 acts da Molière, translatada libramein en romonsch, in: Annalas da la Societad Retorumantscha 9 (1894), S. 49-92.

Tuor, Leo: Suppe, Hahn und Zauberzahl, in: ders.: Auf der Suche nach dem verlorenen Schnee, Zürich: Limmat, 2016, S. 209-217.

Valentin, Flurin: Poesias compostas per l'ütil dellas Scolas, Cuoira: Senti \& Humme, 1863.

Vay von Vaya und Luskod, Péter: Empires and Emperors of Russia, China, Korea, and Japan.

Notes and Recollections, New York: E. P. Dutton, 1906.

Vay von Vaya und Luskod, Péter: A travers la Mandchourie. Notes de voyage, in: Revue des

Deux Mondes, Cinquième periode, Bd. 23, Nr. 1 (1. September 1904), S. 132-163.

Vital, Andrea: Gian Fadri Caderas, in: Annalas da la Societad Retorumantscha 13 (1899), S. 1-36.

Vital, Andrea: Proverbis, in: Annalas da la Societad Retorumantscha 13 (1899), S. 141-162.

Vital, Not: Kec’ \& Frajas. Poesias \& + oter, Ardez: Fundaziun Not Vital, 2019.

Vital, Not: 201 proverbis tradüts da Not Vital in pled da Sent, Ardez: Fundaziun Not Vital, 2017. Vogelsang, Kai: Geschichte Chinas, Stuttgart: Reclam, 2012.

Wiederkehr, Emil: Hunger, Elend und Zwangsarbeit vertreiben die Tibeter aus ihrem Land, in: Die Leiden eines Volkes. Die Tragödie Tibets und der tibetischen Flüchtlinge, hg. von der Schweizer Tibethilfe Solothurn, Solothurn: Veritas, 1961, S. 175-196.

Zhuangzi: Das Buch der Spontaneität. Über den Nutzen der Nutzlosigkeit und die Kultur der Langsamkeit. Das klassische Buch daoistischer Weisheit, übers. von Victor H. Mair und Stephan Schuhmacher, Aitrang: Windpferd, 2008.

Mathias Gredig war wissenschaftlicher Mitarbeiter an der Hochschule der Künste Bern sowie Leiter des Archivs und der Bibliothek der Chesa Planta Samedan. Derzeit forscht er an der Universität Basel und dem Institut für Kulturforschung Graubünden zur Geschichte der Salonorchester im Engadin. Er promovierte mit einer Geschichte der skeptischen Zoomusikologie an der Universität Basel und ist Autor einer Studie zum Cellospiel von Daniil Schafran. 


\title{
Der doppelte Po und die Musik
}

Rätoromanisch-chinesische Studien, besonders zu

Li Po, Harry Partch und Chasper Po

\author{
Herausgegeben von \\ Mathias Gredig, Marc Winter, \\ Rico Valär und Roman Brotbeck \\ Redaktionelle Mitarbeit \\ Daniel Allenbach
}

Königshausen \& Neumann 
Bibliografische Information der Deutschen Nationalbibliothek

Die Deutsche Nationalbibliothek verzeichnet diese Publikation in der Deutschen

Nationalbibliografie; detaillierte bibliografische Daten sind im Internet über http://dnb.d-nb.de abrufbar.

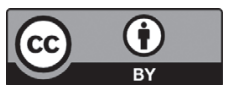

Dieses Werk ist lizenziert unter der Creative Commons Attribution 4.0 Lizenz (BY). Diese Lizenz erlaubt unter Voraussetzung der Namensnennung des Urhebers die Bearbeitung, Vervielfältigung und Verbreitung des Materials in jedem Format oder Medium für beliebige Zwecke, auch kommerziell. (Lizenztext: https://creativecommons.org/ licenses/by/4.0/deed.de) Die Bedingungen der Creative-Commons-Lizenz gelten nur für Originalmaterial. Die Wiederverwendung von Material aus anderen Quellen (gekennzeichnet mit Quellenangabe) wie z. B. Schaubilder, Abbildungen, Fotos und Textauszüge erfordert ggf. weitere Nutzungsgenehmigungen durch den jeweiligen Rechteinhaber.

Erschienen 2021 im Verlag Königshausen \& Neumann GmbH

(C) bei den Autoren

Die Druckvorstufe dieser Publikation wurde vom Schweizerischen Nationalfonds zur Förderung der wissenschaftlichen Forschung unterstützt.

\section{FNSNF}

SCHWEIZERISCHER NATIONALFONDS

ZUR FÖRDERUNG DER WISSENSCHAFTLICHEN FORSCHUNG

Wir danken der Kulturförderung des Kantons Graubünden.

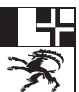

Kulturförderung Graubünden. Amt für Kultur

Promoziun da la cultura dal Grischun. Uffizi da cultura

Promozione della cultura dei Grigioni. Ufficio della cultura

SWIISSLOS

Hochschule der Künste Bern

www.hkb.bfh.ch

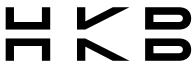

Hochschule der Künste Bern

Haute école des arts de Bern

Bern University of the Arts

Umschlag: skh-softics / coverart

Umschlagabbildung: Lea Gredig

Print-ISBN 978-3-8260-7180-5

PDF-ISBN 978-3-8260-7233-8

DOI $10.26045 /$ po

https.//doi.org/10.36202/9783826072338

Gedruckt auf säurefreiem, alterungsbeständigem Papier

Printed in Germany

www.koenigshausen-neumann.de

www.ebook.de

www.buchhandel.de

www.buchkatalog.de 


\section{Inhalt}

Prolog

Dumenic Andry

Chasper Pos Humor

Renzo Caduff

Chasper Pos rhythmische Versgestaltung - eine shinkende Mähre`?

Rico Valär

Rätoromanische Nachdichtungen chinesischer Lyrik bei

Gian Fadri Caderas und Peider Lansel

Eine Spurensuche

Mathias Gredig

China in rätoromanischen Zeitungen, Zeitschriften

und literarischen Texten

Marion Eggert

Schwalbenflug in Gedichten von Li Bai und Chasper Po

Thomas Geissmann

Die Rolle der Gibbons beim chinesischen Dichter Li Bai

Marc Winter

„Chinas Dichterfürst«

Die Rezeption Li Bais als literarischer Superstar im Westen

Eva Schestag

"A most difficult man«

Ezra Pound als Übersetzer von Li Bai, mit einem Seitenblick auf Shigeyoshi Obata

Odila Schröder

Chinesische Li-Bai-Vertonungen in Jahren der Unruhe 
Mathias Gredig

Quantitative Überlegungen zum Phänomen

der Li-Bai-Vertonungen im Westen

Mit Beobachtungen zu drei Vertonungen des Gedichtes

Chun ye Luo cheng wen di (In einer Frühlingsnacht in Luoyang eine Flöte hören)

\section{Gesine Schröder}

"Die Hüften schwingen sich nun nicht mehr»

Li-Bai-Vertonungen von Komponistinnen

Heinrich Aerni

Li-Bai-Vertonungen in der Schweiz

Matthias Schmidt

Übersetzung ohne Original?

Gustav Mahler, Anton Webern und Li Bai

\section{Christoph Haffter}

Szenen der Selbstenttäuschung

Hanns Eislers Die rote und die weiße Rose nach Li Bai und die Antinomien der Kriegslyrik

Thomas Meyer

„Wunderlich im Spiegelbilde»

Zu einigen Vertonungen des Pavillon-Gedichts

\section{Mathias Gredig}

Gedanken über Li Bais Jing ye si (Gedanken in einer stillen Nacht)

und dessen Vertonungen im Westen

\section{Martin Skamletz}

"I've turned into a great reviser."

Lee Hoibys Vertonung von Li Bais The River-Merchant's Wife: A Letter

und ihr Bezug zu Harry Partch

\section{Martin Skamletz}

"Of course I am a weak shadow of Lee Hoiby as a Kitharist."

Five letters by Harry Partch, 1948-1958

\section{Marc Kilchenmann}

Ben Johnstons Verhältnis zu Harry Partch und seine Three Chinese Lyrics 
Eleni Ralli

Parallelen und Modifikationen der Notation in verschiedenen Quellen

von Harry Partchs Seventeen Lyrics by Li Po

Schwierigkeiten und Transkriptionsvorschläge

Charles Corey

Gesture and Intention in the Art Songs of Harry Partch

Caspar Johannes Walter

Sprechmelodie als Quelle von Melodik und Harmonik

The Intruder aus Harry Partchs Li-Bai-Vertonungen

Roman Brotbeck

Der Sprechgesang bei Arnold Schönberg und Harry Partch

Eine Annäherung

Namensregister 